University of Nebraska - Lincoln

DigitalCommons@University of Nebraska - Lincoln

Faculty Publications: Department of Entomology

$11-21-2019$

\title{
Transcriptional responses of soybean aphids to sublethal insecticide exposure
}

\author{
Laramy S. Enders \\ University of Nebraska-Lincoln, lenders2@unl.edu \\ Leslie C. Rault \\ University of Nebraska - Lincoln, Irault2@unl.edu \\ Tiffany Heng-Moss \\ University of Nebraska-Lincoln, thengmoss2@unl.edu \\ Blair Siegfried \\ University of Florida, bsiegfried1@ufl.edu \\ Nicholas J. Miller \\ University of Nebraska-Lincoln, nmiller11@iit.edu
}

Follow this and additional works at: https://digitalcommons.unl.edu/entomologyfacpub

Part of the Entomology Commons, and the Molecular Genetics Commons

Enders, Laramy S.; Rault, Leslie C.; Heng-Moss, Tiffany; Siegfried, Blair; and Miller, Nicholas J., "Transcriptional responses of soybean aphids to sublethal insecticide exposure" (2019). Faculty Publications: Department of Entomology. 826.

https://digitalcommons.unl.edu/entomologyfacpub/826

This Article is brought to you for free and open access by the Entomology, Department of at DigitalCommons@University of Nebraska - Lincoln. It has been accepted for inclusion in Faculty Publications: Department of Entomology by an authorized administrator of DigitalCommons@University of Nebraska - Lincoln. 


\title{
Transcriptional responses of soybean aphids to sublethal insecticide exposure
}

\author{
Laramy S. Enders, ${ }^{1,2}$ Leslie C. Rault, ${ }^{1}$ \\ Tiffany M. Heng-Moss, ${ }^{1}$ Blair D. Siegfried, ${ }^{1,3}$ \\ \& Nicholas J. Miller ${ }^{1,4}$
}

\footnotetext{
1 Department of Entomology, University of Nebraska-Lincoln, Entomology Hall, Lincoln, NE, 68583, USA

2 Department of Entomology, Purdue University, 901 W State St, West

Lafayette, IN, 47907, USA

3 Department of Entomology and Nematology, University of Florida, 1881

Natural Area Drive, Gainesville, FL, 32611, USA

4 Department of Biology, Illinois Institute of Technology, 3101 S Dearborn St, Chicago, IL, 60616, USA
Corresponding author - N. J. Miller, Department of Biology, Illinois Institute of Technology, 3101 S. Dearborn St., Chicago, IL, 60616, USA; email nmiller11@iit.edu
}

\begin{abstract}
Insecticides are a key tool in the management of many insect pests of agriculture, including soybean aphids. The selection imposed by insecticide use has often lead to the evolution of resistance by the target pest through enhanced detoxification mechanisms. We hypothesised that exposure of insecticide-susceptible aphids to sublethal doses of insecticides would result in the up-regulation of genes involved in detoxification of insecticides, revealing the genes upon which selection might act in the field. We used the soybean aphid biotype 1 reference genome, version 6.0 as a reference to analyze RNA-Seq data. We identified multiple genes with potential detoxification roles that were up-regulated $12 \mathrm{~h}$ after sublethal exposure to
\end{abstract}

Published in Insect Biochemistry and Molecular Biology 118 (2020), 103285, 7p.

DOI: 10.1016/j.ibmb.2019.103285

Copyright (c) 2019. Published by Elsevier Ltd. Used by permission.

Submitted 7 January 2019; revised 7 November 2019; accepted 18 November 2019;

published 21 November 2019. 
esfenvalerate or thiamethoxam. However, these genes were part of a dramatic burst of differential gene expression in which thousands of genes were up- or down-regulated, rather than a defined response to insecticides. Interestingly, the transcriptional burst observed at $12 \mathrm{~h}$ s declined dramatically by 24 -hrs post-exposure, suggesting a general stress response that may become fine-tuned over time.

Keywords: esfenvalerate, RNA-seq, Gene expression, Aphis glycines, Thiamethoxam

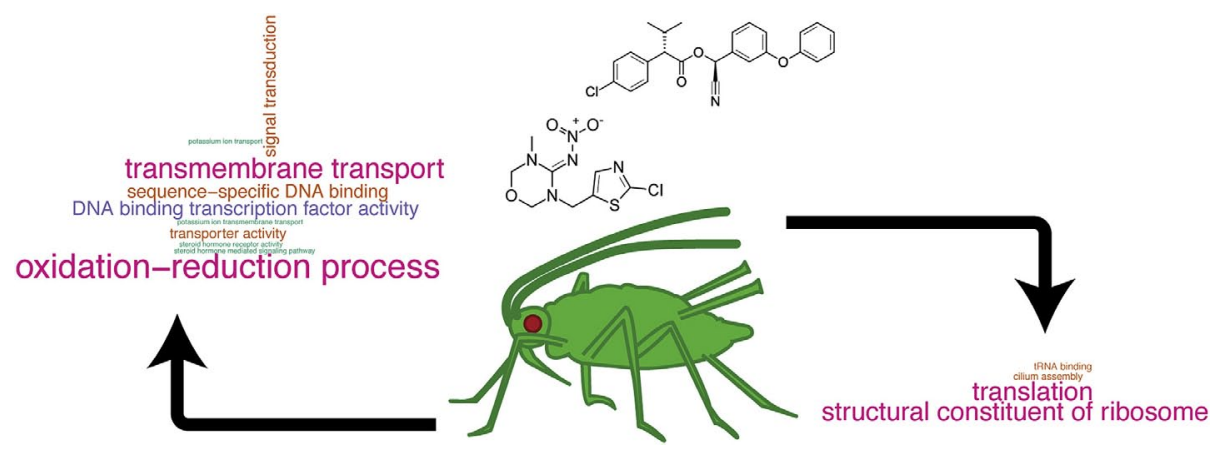

\section{Introduction}

Management of aphid pests within agro-ecosystems relies extensively on the use of insecticides. Organophosphates, carbamates, pyrethroids and neonicotinoids are the most common insecticidal groups used to control aphids (Koch et al., 2018). These toxins generally target critical functions, such as transmission of nerve impulses, cellular respiration and lipid biosynthesis (Nauen et al., 2011; Yu, 2011). However, intensive use of insecticides worldwide has lead to the evolution of resistance in many aphid pests, most notably Myzus persicae and Aphis gossypii (Bass et al., 2014; Carletto et al., 2010). At least 20 aphid species, including the invasive soybean aphid (Aphis glycines), have developed resistance to multiple groups of insecticides (Foster et al., 2007; Hanson et al., 2017).

Several mechanisms exist in aphids that render individuals insensitive to chemical insecticides, including mutations of targeted receptor sites, reduced cuticular penetration and heightened activity of detoxification enzymes (Bass et al., 2014; Foster et al., 2007). Activation of genes involved in various phases of xenobiotic detoxification appears to be a core mechanism by which aphids counteract exposure to insecticidal compounds (Enders and Miller, 2016). Transcriptional responses of aphids exposed to several insecticides show increased expression of many detoxifying enzymes, including cytochrome P450 microsomal monooxygenases, esterases, and 
glutathione-S-transferases (Cabrera-Brandt et al., 2014; Pan et al., 2015; Silva et al., 2012; Wu et al., 2018; Xi et al., 2015). For example, among 183 genes up-regulated in a pirimicarb-sensitive $M$. persicae genotype, 60 were involved in xenobiotic detoxification (Silva et al., 2012).

Although detoxification is a primary coping mechanism in aphids, transcriptomic studies have revealed that a greater level of complexity underlies response to insecticides than previously believed (Enders and Miller, 2016). A significant portion of the aphid transcriptome is altered under selective pressure from insecticide stress. Hundreds of genes involved in a broad spectrum of pathways are differentially expressed in resistant genotypes (Pan et al., 2015; Xi et al., 2015). For example, general stress responsive genes associated with restoration of homeostasis are differentially expressed in insecticide stressed aphids, such as heat shock proteins and peptidases that interact with damaged proteins (Cabrera-Brandt et al., 2014; Silva et al., 2012; Xi et al., 2015). Increased expression of cuticular proteins also likely functions as a first line of defense against insecticides, by reducing permeability through the aphid exoskeleton (Silva et al., 2012). Finally, comparison of transcriptional changes among genotypes with various resistance mechanisms demonstrates aphids exhibit considerable plasticity in gene expression when exposed to insecticides (Silva et al., 2012).

Despite considerable advances in our understanding of aphid molecular responses to insecticides, the underlying mechanisms responsible for resistance remain uncharacterized in several species, including the soybean aphid. Approximately 15 years after being introduced into North America, pyrethroid resistant populations of $A$. glycines were documented in Minnesota and lowa (Hanson et al., 2017). A recent study found increased esterase and cytochrome P450 (CYP) activity in laboratory populations of $A$. glycines selected for pyrethroid resistance (Xi et al., 2015). However, it is unclear to what extent general detoxification mechanisms are involved in response to multiple pyrethroids or additional insecticide classes used to control A. glycines. We therefore aimed to characterize the transcriptional response of A. glycines exposed to sublethal doses of two insecticides: thiamethoxam (neonicotinoid) and esfenvalerate (pyrethroid). We hypothesised that differential gene expression would reveal insecticide responsive detoxification genes that may respond to selection and lead to resistance evolution. 


\section{Material and methods}

\subsection{Insect rearing and stress treatments}

The colony of soybean aphids (A. glycines) used in this experiment was established in 2011 from a single viviparous parthenogenetic female collected in Madison, Wisconsin. Microsatellite markers (Kim et al., 2010; Michel et al., 2009) confirmed this colony consisted of a single genotype (Enders et al., 2014). In addition, the colony was unable to successfully colonize a panel of soybean varieties containing various resistance genes (Rag: Resistance to Aphis glycines) and was therefore considered a biotype 1 clonal line (Enders et al., 2014). Aphids were continuously maintained in a growth chamber $\left(24 \pm 1^{\circ} \mathrm{C}, 16: 8\right.$ photoperiod) on a single soybean plant (variety KS4202) grown in a plastic Cone-tainer (Ray Leach Cone-tainer, Hummert International, Earth (ity, MO) and covered by a custom fitted cylindrical plastic cage $(30.5 \mathrm{~cm} \times 4.4 \mathrm{~cm})$. Soybean variety KS4202 was used for aphid colony maintenance because it does not adversely affect aphid survival or development and is tolerant of large populations (Enders et al., 2014; Pierson et al., 2010). All soybean plants used for aphid colony maintenance and experimental treatments were grown in a greenhouse (16L:8D photoperiod), using a potting medium comprised of peat moss, perlite, pine bark, and vermiculite (Fafard 3B Mix).

Plants of a standard aphid susceptible soybean variety SD76R (Chiozza et al., 2010) were grown under greenhouse conditions to the V2 vegetative stage for use in age-synchronizing adult aphids and experimental treatments. Groups of aphids were age-synchronized prior to exposure to insecticide stress and control treatments by allowing adults from the aphid colony to produce offspring for $48 \mathrm{~h}$ in a growth chamber $\left(24 \pm 1{ }^{\circ} \mathrm{C}, 16 \mathrm{~L}: 8 \mathrm{D}\right.$ hours photoperiod). When age-synchronized offspring reached reproductive age ( 7 days old) they were exposed to the following treatments: 1 ) control conditions (no insecticide) 2) Esfenvalerate stress $\left(\mathrm{LC}_{50}=10 \mathrm{ng} / \mu \mathrm{l}\right)$ and 3) Thiamethoxam stress $\left(\mathrm{LC}_{50}=10 \mathrm{ng} / \mu \mathrm{l}\right)$. We used a modified aphid-dip bioassay technique (Chandrasena et al., 2011) to expose groups of age-synchronized adult aphids to each insecticide or control solution. Preliminary experiments determined the $\mathrm{LC}_{50}$ for each insecticide that resulted in approximately $50 \%$ mortality $48 \mathrm{hs}$ post-exposure was $10 \mathrm{ng} / \mu \mathrm{l}$. 
Insecticide solutions were prepared by dissolving in acetone and then diluting with distilled water to reach the desired concentration.

Groups of 40 adult aphids were dipped for $10 \mathrm{~s}$ in each of the 3 treatment solutions: Control ( $0.05 \%$ acetone in distilled water), Esfenvalerate $(10 \mathrm{ng} / \mu \mathrm{l})$, and Thiamethoxam $(10 \mathrm{ng} / \mu \mathrm{l})$. The aphids were then transferred with a paint brush to a single V1 trifoliate of a susceptible soybean plant and covered with a custom-built plastic Petridish cage $(8.9 \mathrm{~cm} \times 2.5 \mathrm{~cm})$. Nine replicate cages were set up for each treatment. Aphids were harvested at 12 and $24 \mathrm{~h}$ post exposure from independent cages, flash-frozen in liquid nitrogen and stored at $-80^{\circ} \mathrm{C}$ for further transcriptomic processing. Survival and nymph production were also measured at each time point.

\subsection{Transcriptomic methods and analysis}

Total RNA was isolated and purified from groups of 30 whole apterous adults using a Qiagen RNeasy extraction kit according to manufacturer protocols. Four replicate RNA samples were prepared for each of the 3 experimental treatments ( 2 insecticides and control) at each time point ( $12 \mathrm{~h}$ and $24 \mathrm{hr}$ ) by randomly pooling aphids from across $4-5$ replicate cages (24 total biological replicates). RNA integrity was confirmed using an Agilent 2100 Bioanalyzer. RNA-Seq libraries were prepared, pooled and sequenced on two lanes of an Illumina HiSeq 2000 platform at the University of Nebraska Medical Center Genomics Core facility. Sequencing resulted in between $6,596,272$ and $14,656,030$ (mean 11,253,320) pairs of 100 nucleotide reads per biological replicate. Read data were deposited with the NCBI Sequence Read Archive under BioProject PRJNA515901.

Technical sequences (e.g. sequencing adapters) and regions of lowquality sequence were removed from reads using Trimmomatic (Bolger et al., 2014). Trimmed reads were aligned to the Aphis glycines biotype 1 reference genome, version 6, using HISAT2 (Kim et al., 2015). The number of sequenced fragments mapping to each gene in the Aphis glycines official gene set (OGS) version 6.0 was computed for each RNASeq library using featureCounts (Liao et al., 2014). Tests for differential gene expression between each insecticide/time point treatment and the corresponding control were performed with DESeq2 (Love et al., 2014). Genes were declared significantly differentially-expressed at a false discovery rate (Benjamini and Hochberg, 1995) of 0.1. 
Putative functions of select differentially-expressed genes were inferred from the results of InterProScan and Blast2GO analysis of the OGS 6.0 gene models prepared by the Bioinformatics Platform for Agrosystem Arthropods (BIPPA) and an additional Blast2GO analysis provided by Ravi Kiran Donthu, Puerto Rico Science, Technology \& Research Trust, San Juan, Puerto Rico. Gene Ontology-term enrichment analyses for sets of differentially-expressed genes were performed using GOSeq (Young et al., 2010) using a consolidated, non-redundant set of gene to $\mathrm{GO}$ term mappings prepared from the sources given above. GO terms were declared significantly overrepresented at a false discovery rate of 0.1 . Ancestor charts of overrepresented GO terms were generated using the online tools provided by the EBI QuickGo site (www.ebi.ac.uk/QuickGO). Genes with possible detoxification roles were identified by searching the "description" field of the InterProScan results for case-insensitive matches to the strings "Cytochrome P450", "ABC transporter", "glutathione S-transferase" and "carboxylesterase".

\section{Results}

\subsection{Overall transcriptional response to insecticide treatments}

The number of sequenced fragments that were mapped to gene models in the official gene set version 6.0 ranged from 2,279,371 to $9,411,020$ (mean 6,400,514) per sample.

The number of genes that were significantly differentially expressed changed rapidly over time for both insecticides (Table 1, Fig. 1). At $12 \mathrm{~h}$ post-exposure, thousands of genes were differentially expressed (Table 1, Fig. 1). At $24 \mathrm{~h}$ post-exposure, the number of differentially expressed genes had declined to a few hundred for

Table 1. Total numbers of differentially expressed genes.

\begin{tabular}{llllll} 
& \multicolumn{2}{l}{ Esfenvalerate } & & \multicolumn{2}{c}{ Thiamethoxam } \\
\cline { 2 - 3 } \cline { 5 - 6 } & $12 h$ & & & $12 h$ & $24 h$ \\
\hline Up-Regulated & 4163 & 131 & & 2177 & 1 \\
Down-Regulated & 4169 & 72 & & 1982 & 6 \\
\hline
\end{tabular}



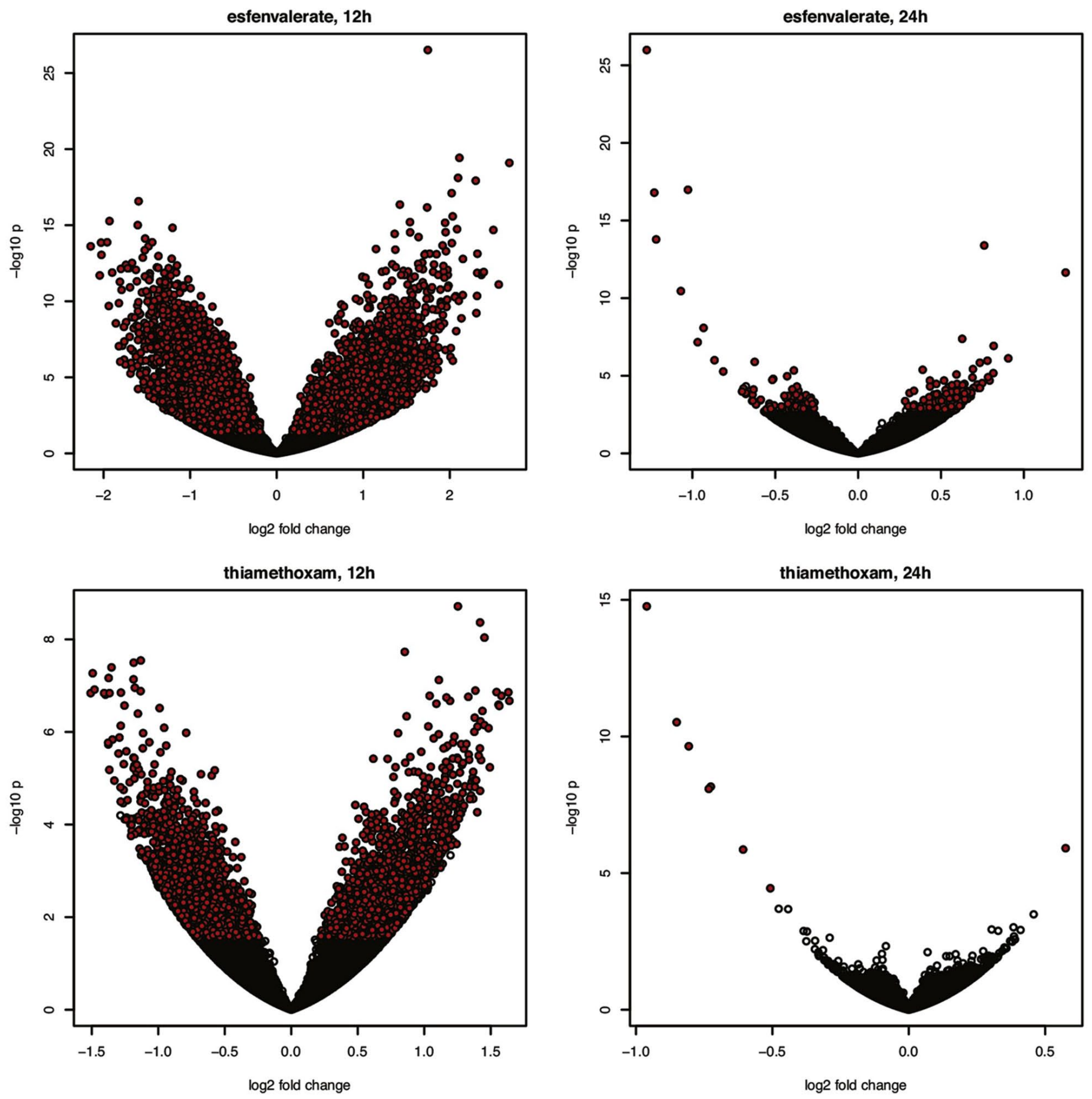

Fig. 1. Volcano plots showing changes in gene expression, relative to control conditions, 12 and $24 \mathrm{~h}$ after exposure to esfenvalerate or thiamethoxam. Red circles indicate genes that were significantly differentially-expressed at a false discovery rate of 0.1 . 
Up-regulated

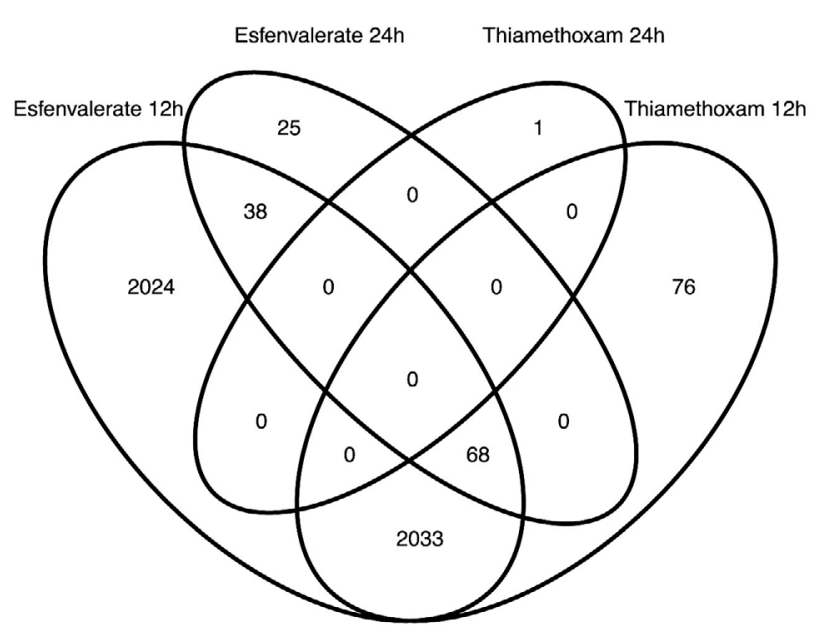

Down-regulated

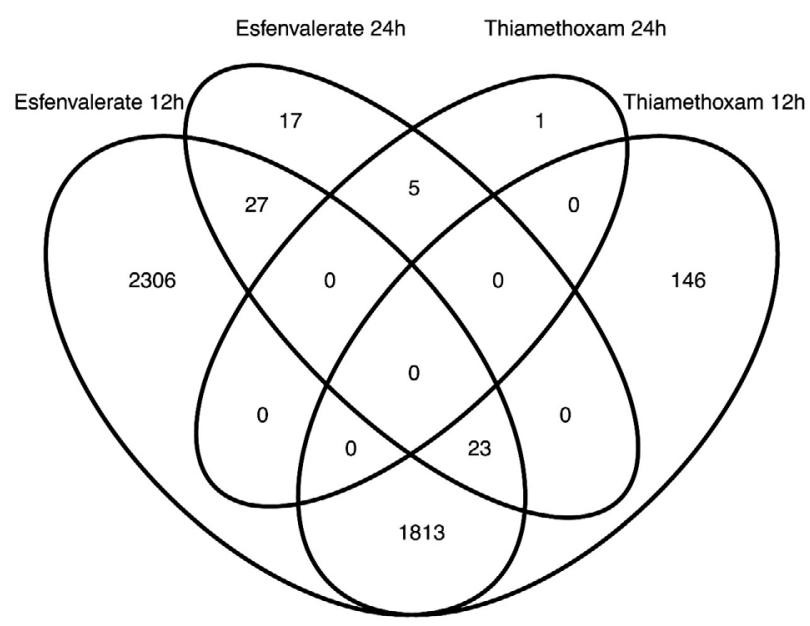

Fig. 2. Venn diagrams showing the numbers of up- and down-regulated transcripts after exposure to two insecticides.

esfenvalerate and less than ten for thiamethoxam (Table 1, Fig. 1). There was considerable overlap between the two insecticides in the genes that were significantly up- or down-regulated in response to exposure after $12 \mathrm{~h}$ (Fig. 2). To a lesser extent, there was also some overlap between genes that were up- or down-regulated 12 and 24 $\mathrm{h}$ after exposure to esfenvalerate. Similarly, some genes that were up- and down-regulated following exposure to esfenvalerate were shared with those up- or down-regulated $12 \mathrm{~h}$ after exposure to thiamethoxam (Fig. 2).

GO-term enrichment analyses of the genes that were differentially regulated in response to each insecticide or to both insecticides, $12 \mathrm{~h}$ after exposure, revealed some consistent patterns. Overrepresented GO terms associated with genes that were upregulated were mainly indicative of signaling, regulation of transcription and oxidation/reduction processes (Tables 2-4). Overrepresented GO terms associated with genes that were downregulated were mostly indicative of translation and protein synthesis (Tables 5-7). Ancestor charts of overrepresented GO terms are given in Supplementary Figs. S1-S6. 
Table 2. Overrepresented $\mathrm{GO}$ terms associated with genes up-regulated $12 \mathrm{~h}$ after exposure to esfenvalerate. CC: cellular component, MF: molecular function, BP: biological process, $q$ : false discovery rate $q$-value, $N$ : number of genes in category.

\begin{tabular}{|c|c|c|c|c|}
\hline GO term & Ontology & Description & $q$ & $N$ \\
\hline GO:0043565 & MF & sequence-specific DNA binding & $<0.01$ & 115 \\
\hline GO:0003700 & MF & DNA binding transcription factor activity & $<0.01$ & 116 \\
\hline GO:0005215 & MF & transporter activity & $<0.01$ & 68 \\
\hline GO:0005509 & MF & calcium ion binding & $<0.01$ & 97 \\
\hline GO:0003707 & MF & steroid hormone receptor activity & 0.062 & 18 \\
\hline GO:0004930 & MF & G-protein coupled receptor activity & 0.064 & 51 \\
\hline GO:0102336 & MF & 3-oxo-arachidoyl-CoA synthase activity & 0.083 & 8 \\
\hline GO:0102337 & MF & 3-oxo-cerotoyl-CoA synthase activity & 0.083 & 8 \\
\hline GO:0102338 & MF & 3-oxo-lignoceronyl-CoA synthase activity & 0.083 & 8 \\
\hline GO:0102756 & MF & very-long-chain 3-ketoacyl-CoA synthase activity & 0.083 & 8 \\
\hline GO:0055114 & $\mathrm{BP}$ & oxidation-reduction process & $<0.01$ & 227 \\
\hline GO:0055085 & $\mathrm{BP}$ & transmembrane transport & $<0.01$ & 159 \\
\hline GO:0006355 & $\mathrm{BP}$ & regulation of transcription, DNAtemplated & $<0.01$ & 199 \\
\hline GO:0007186 & $\mathrm{BP}$ & G-protein coupled receptor signaling pathway & $<0.01$ & 62 \\
\hline GO:0007165 & $\mathrm{BP}$ & signal transduction & 0.01 & 89 \\
\hline GO:0006813 & $\mathrm{BP}$ & potassium ion transport & 0.038 & 15 \\
\hline GO:0006633 & $\mathrm{BP}$ & fatty acid biosynthetic process & 0.039 & 21 \\
\hline GO:0043401 & $\mathrm{BP}$ & steroid hormone mediated signaling pathway & 0.049 & 19 \\
\hline GO:0007155 & $\mathrm{BP}$ & cell adhesion & 0.049 & 33 \\
\hline GO:0008152 & $\mathrm{BP}$ & metabolic process & 0.055 & 118 \\
\hline GO:0016310 & $\mathrm{BP}$ & phosphorylation & 0.065 & 38 \\
\hline GO:0005975 & $\mathrm{BP}$ & carbohydrate metabolic process & 0.083 & 72 \\
\hline GO:0016020 & $\mathrm{CC}$ & membrane & $<0.01$ & 272 \\
\hline GO:0016021 & $\mathrm{CC}$ & integral component of membrane & $<0.01$ & 1162 \\
\hline
\end{tabular}

Table 3. Overrepresented $\mathrm{GO}$ terms associated with genes up-regulated $12 \mathrm{~h}$ after exposure to thiamethoxam. CC: cellular component, MF: molecular function, BP: biological process, $q$ : false discovery rate $q$-value, $N$ : number of genes in category.

\begin{tabular}{|c|c|c|c|c|}
\hline GO term & Ontology & Description & $q$ & $N$ \\
\hline GO:0043565 & MF & sequence-specific DNA binding & $<0.01$ & 63 \\
\hline GO:0005215 & MF & transporter activity & $<0.01$ & 47 \\
\hline GO:0003700 & MF & DNA binding transcription factor activity & $<0.01$ & 66 \\
\hline GO:0003707 & MF & steroid hormone receptor activity & $<0.01$ & 15 \\
\hline GO:0055085 & BP & transmembrane transport & $<0.01$ & 107 \\
\hline GO:0006813 & BP & potassium ion transport & $<0.01$ & 14 \\
\hline GO:0055114 & BP & oxidation-reduction process & $<0.01$ & 130 \\
\hline GO:0071805 & $\mathrm{BP}$ & potassium ion transmembrane transport & 0.014 & 15 \\
\hline GO:0043401 & BP & steroid hormone mediated signaling pathway & 0.016 & 15 \\
\hline GO:0007165 & $\mathrm{BP}$ & signal transduction & 0.035 & 58 \\
\hline GO:0016021 & $\mathrm{CC}$ & integral component of membrane & $<0.01$ & 670 \\
\hline GO:0016020 & $\mathrm{CC}$ & membrane & 0.082 & 163 \\
\hline
\end{tabular}


Table 4. Overrepresented GO terms associated with genes up-regulated $12 \mathrm{~h}$ after exposure to esfenvalerate and $12 \mathrm{~h}$ after exposure to thiamethoxam. CC: cellular component, MF: molecular function, BP: biological process, $q$ : false discovery rate $q$-value, $N$ : number of genes in category.

\begin{tabular}{|c|c|c|c|c|}
\hline GO term & Ontology & Description & $q$ & $N$ \\
\hline GO:0043565 & MF & sequence-specific DNA binding & $<0.01$ & 61 \\
\hline GO:0005215 & MF & transporter activity & $<0.01$ & 46 \\
\hline GO:0003700 & MF & DNA binding transcription factor activity & $<0.01$ & 65 \\
\hline GO:0003707 & MF & steroid hormone receptor activity & $<0.01$ & 15 \\
\hline GO:0055085 & $\mathrm{BP}$ & transmembrane transport & $<0.01$ & 105 \\
\hline GO:0006813 & $\mathrm{BP}$ & potassium ion transport & $<0.01$ & 14 \\
\hline GO:0055114 & $\mathrm{BP}$ & oxidation-reduction process & $<0.01$ & 126 \\
\hline GO:0071805 & $\mathrm{BP}$ & potassium ion transmembrane transport & $<0.01$ & 15 \\
\hline GO:0043401 & $\mathrm{BP}$ & steroid hormone mediated signaling pathway & 0.01 & 15 \\
\hline GO:0007165 & $\mathrm{BP}$ & signal transduction & 0.049 & 56 \\
\hline GO:0016021 & $\mathrm{CC}$ & integral component of membrane & $<0.01$ & 646 \\
\hline
\end{tabular}

Table 5. Overrepresented GO terms associated with genes down-regulated $12 \mathrm{~h}$ after exposure to esfenvalerate. CC: cellular component, MF: molecular function, BP: biological process, $q$ : false discovery rate $q$-value, $N$ : number of genes in category.

\begin{tabular}{lllrr} 
GO term & Ontology & Description & $q$ & $N$ \\
\hline GO:0003735 & MF & structural constituent of ribosome & $<0.01$ & 94 \\
GO:0003723 & MF & RNA binding & $<0.01$ & 121 \\
GO:0005524 & MF & ATP binding & $<0.0$ & 1357 \\
GO:0008080 & MF & N-acetyltransferase activity & 0.017 & 18 \\
GO:0019843 & MF & rRNA binding & 0.043 & 10 \\
GO:0016887 & MF & ATPase activity & 0.043 & 56 \\
GO:0006412 & BP & translation & $<0.01$ & 93 \\
GO:0006396 & BP & RNA processing & $<0.01$ & 46 \\
GO:0002181 & BP & cytoplasmic translation & $<0.01$ & 11 \\
GO:0006886 & BP & intracellular protein transport & 0.024 & 53 \\
GO:0032259 & BP & methylation & 0.028 & 29 \\
GO:0045859 & BP & regulation of protein kinase activity & 0.039 & 8 \\
GO:0090305 & BP & nucleic acid phosphodiester bond hydrolysis & 0.039 & 25 \\
GO:0002098 & BP & tRNA wobble uridine modification & 0.052 & 9 \\
GO:0006367 & BP & transcription initiation from RNA polymerase II promoter & 0.062 & 9 \\
GO:0005840 & CC & ribosome & $<0.01$ & 91 \\
GO:0005622 & CC & intracellular & $<0.01$ & 193 \\
GO:0022625 & CC & cytosolic large ribosomal subunit & $<0.01$ & 13 \\
GO:0022627 & CC & cytosolic small ribosomal subunit & $<0.01$ & 8 \\
GO:0031011 & CC & Ino80 complex & $<0.01$ & 14 \\
GO:0005759 & CC & mitochondrial matrix & 0.012 & 14 \\
GO:0019013 & CC & viral nucleocapsid & 0.039 & 14 \\
GO:0030529 & CC & intracellular ribonucleoprotein complex & 0.052 & 22 \\
GO:0005815 & CC & microtubule organizing center & 0.09 & 14 \\
\hline & & & & \\
\hline
\end{tabular}


Table 6. Overrepresented GO terms associated with genes down-regulated $12 \mathrm{~h}$ after exposure to thiamethoxam. CC: cellular component, MF: molecular function, BP: biological process, $q$ : false discovery rate $q$-value, $N$ : number of genes in category.

\begin{tabular}{lllrr} 
GO term & Ontology & Description & $q$ & $N$ \\
\hline GO:0003735 & MF & structural constituent of ribosome & $<0.01$ & 27 \\
GO:0000049 & MF & tRNA binding & 0.028 & 8 \\
GO:0006412 & BP & translation & $<0.01$ & 27 \\
GO:0060271 & BP & cilium assembly & $<0.01$ & 8 \\
GO:0005840 & CC & ribosome & $<0.01$ & 26 \\
\hline
\end{tabular}

Table 7. Overrepresented GO terms associated with genes down-regulated $12 \mathrm{~h}$ after exposure to esfenvalerate and $12 \mathrm{~h}$ after exposure to thiamethoxam. CC: cellular component, MF: molecular function, BP: biological process, $q$ : false discovery rate $q$-value, $N$ : number of genes in category.

\begin{tabular}{lllrr} 
GO term & Ontology & Description & $q$ & $N$ \\
\hline GO:0003735 & MF & structural constituent of ribosome & 0.014 & 26 \\
GO:0000049 & MF & tRNA binding & 0.021 & 8 \\
GO:0060271 & BP & cilium assembly & 0.014 & 8 \\
GO:0006412 & BP & translation & 0.014 & 26 \\
GO:0005840 & CC & ribosome & 0.018 & 24 \\
\hline
\end{tabular}

\subsection{Putative functions of highly differentially-expressed genes}

The InterProScan and Blast2GO results for the 20 most strongly up and down-regulated genes, relative to controls, for each condition were inspected to infer putative gene function. In the case of thiamethoxam $24 \mathrm{~h}$ after treatment, fewer genes were inspected as only one gene was significantly up-regulated and six genes significantly down-regulated. Details of the inferred functions of strongly differentially expressed genes are given in Supplemental Tables S1-S6.

Two genes were strongly upregulated, relative to controls, $12 \mathrm{~h}$ after treatment with either esfenvalerate or thiamethoxam. Gene AG6014660 was a putative hexokinase. GO terms associated with AG6014660 indicated possible roles in glycolysis or glucose homeostasis. The upregulation of AG6014660 may represent part of a general stress response, as changes in energy metabolism are a common feature of stress responses in aphids (Enders and Miller, 2016). Gene AG6027850 was annotated as a putative tropomyosin gene. Blast2GO results for AG6027850 also indicated nucleic acid binding and alaninine-tRNA ligase functions, which are not characteristic of 
tropomyosin. A blastx search of the NCBI non-redundant protein database revealed strong similarity between the first 81 amino acid residues encoded by AG6027850 (essentially, exon 1) and multiple aphid tropomyosins. Investigation of nearby gene models on the BIPPA genome browser identified two other gene models with blastx hits to insect tropomyosins. It is likely that AG6027850 represents part of a tropomyosin gene that is fragmented into multiple gene models.

A putative $\alpha$-tocopherol transporter gene was highly-expressed, relative to controls, $12 \mathrm{~h}$ after exposure to esfenvalerate. This may also represent part of a general stress response as $\alpha$-tocopherol is known to protect against oxidative stress in Drosophila (Bahadorani et al., 2008). Similar to the tropomyosin gene, blastx searches suggested that the $\alpha$-tocopherol transporter gene was fragmented into at least two adjacent gene models (AG6026920, AG6026921), possibly with one or more undetected exons in-between. Two probable membrane-bound Ras protein genes (AG6034507, AG6032677), likely to be involved in G-protein mediated signaling were highly expressed $12 \mathrm{~h}$ after exposure to thiamethoxam.

The most strongly down-regulated genes, relative to controls, 12 $\mathrm{h}$ after exposure to either esfenvalerate or thiamethoxam were overwhelmingly genes with no identifiable function or unidentified membrane proteins (Supplemental Tables S3 and S4). Of the handful of genes that were strongly differentially expressed $24 \mathrm{~h}$ after exposure to thiamethoxam, none had an identifiable function.

Genes showing strong differential expression $24 \mathrm{~h}$ after exposure to esfenvalerate (Supplemental Tables S5 and S6) frequently had no known function or were unidentified membrane proteins. For those genes for which function could be inferred, no obvious common pathways or processes were apparent. One notable highly-expressed gene, AG6020067, had a putative role in glucuronidation in phase II metabolism of xenobiotic compounds. Conversely, a putative cytochrome P450 monooxygenase gene (AG6003000) was strongly down-regulated, relative to controls.

\subsection{Transcriptional response of detoxification-related genes}

The total number of cytochrome P450 monooxygenase, $A B C$ transporter, glutathione-S-transferase and carboxylesterase genes identified in the OGS were $60,70,15$ and 35 , respectively. Appreciable 

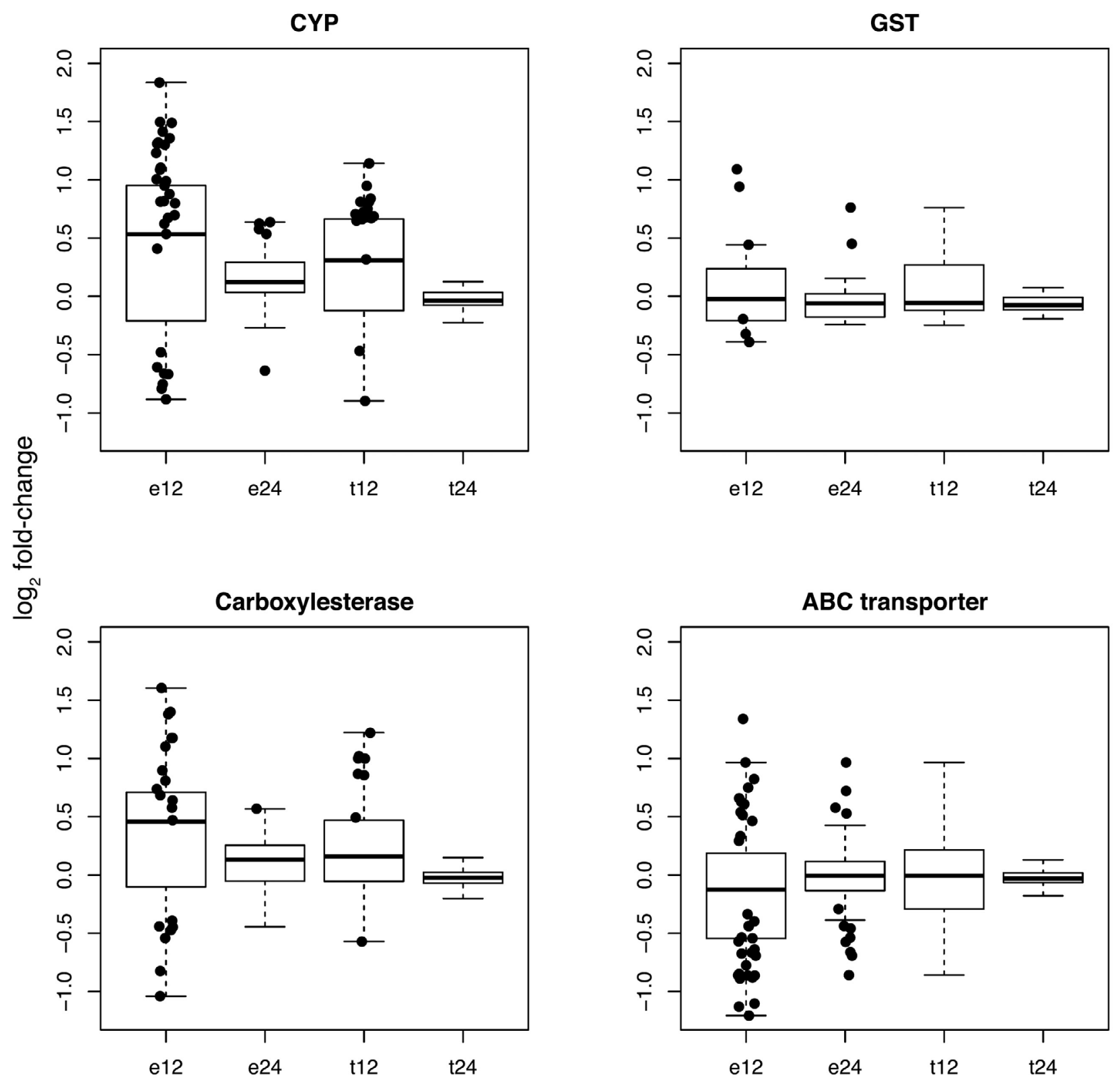

Fig. 3. Distributions of changes in expression ( $\log _{2}$ fold-change, relative to controls) of gene families commonly associated with detoxification of insecticides. Dots denote genes with significant changes in expression at a false discovery rate of 0.1 . CYP: cytochrome P450 monooxygenases, GST: glutathione-S-transferases, e12: 12 $\mathrm{h}$ after exposure to esfenvalerate, e24: $24 \mathrm{~h}$ after exposure to esfenvalerate, t12: 12 $\mathrm{h}$ after exposure to thiamethoxam, t24: $24 \mathrm{~h}$ after exposure to thiamethoxam.

numbers of these genes were among those that were differentially expressed in response to insecticide treatments, especially $12 \mathrm{~h}$ postexposure (Fig. 3, Supplemental Tables S7-S10). The magnitude of 
up- or downregulation of the potential detoxification-related genes, as estimated by log 2 fold-change relative to control conditions, was not significantly different from that of other differentially-expressed genes (Wilcox test $p$-values $>0.15$ ).

\section{Discussion}

When exposed to insecticides the prevailing response across many aphid species is activation of xenobiotic detoxification. For example, resistance to neonicotinoids is associated with overexpression of CYPs in M. persicae (Bass et al., 2014), A. gossypii (Pan et al., 2015; Wu et al., 2018), Aphis craccivora (Abdallah et al., 2016) and Rhopalosiphum padi (Wang et al., 2018). Enhanced detoxification is also reportedly involved in the ability of Chinese $A$. glycines populations to overcome pyrethroid insecticides (Xi et al., 2015). However, it remains unclear whether similar mechanisms underlie resistance observed in A. glycines populations invasive to North America (Hanson et al., 2017). We therefore exposed soybean aphids to sublethal doses of two commonly used insecticides (esfenvalerate and thiamethoxam) and measured transcriptional changes at $12 \mathrm{~h} \mathrm{~s}$ and $24 \mathrm{~h} \mathrm{~s}$ post-exposure in order to identify genetic mechanisms that could potentially contribute to resistance evolution. Overall, we identified multiple genes with potential detoxification roles that were up-regulated in response to both insecticides, but these genes were part of a dramatic transcriptional burst involving thousands of differentially expressed genes that occurred $12 \mathrm{~h}$ s postexposure and largely dissipated by $24 \mathrm{~h} \mathrm{~s}$.

In contrast to previous research, soybean aphids exposed to sublethal doses of insecticide in the current study did not exhibit a strong detoxification response, relative to overall transcriptional changes. differentially expressed following insecticide exposure, they were neither significantly overrepresented nor significantly strongly up- or downregulated, compared to other differentially expressed genes. Three main factors could explain this lack of a distinctive detoxification response in the current study: 1) route or method of insecticide exposure 2) differences in prior history of exposure to insecticides across laboratory populations and 3) method used to measure gene expression (RNA-Seq vs qRT-PCR). 
In the current study aphids were dipped directly into insecticide solution (i.e. aphid dip bioassay), therefore absorption through the cuticle is likely the primary route of exposure. However, many studies utilize either leaf-dip or detached-leaf bioassays (e.g. Magalhaes et al., 2008), where insecticides are coated onto leaves or taken up systemically by the plant prior to aphid infestation and exposure therefore involves direct ingestion. A number of studies reporting enhanced detoxification in response to insecticides have used leaf-dip methods (Abdallah et al., 2016; Pan et al., 2015; Wu et al., 2018), including recent work in A. glycines (Xi et al., 2015). Our results suggest molecular responses vary depending on the route of insecticide exposure. Aphids may mount a stronger xenobiotic detoxification response when insecticides are ingested as opposed to absorbed through the cuticle.

In laboratory populations of $A$. glycines selected for pyrethroid resistance over multiple generations (Xi et al., 2015) increased expression of esterases and CYPs has been observed. In contrast, we measured transcriptional responses using a susceptible $A$. glycines clone with no prior history of exposure to insecticides. Although we found several CYPs differentially expressed in aphids exposed to insecticides (Fig. 3, Supplemental Table S7), detoxification was not a dominant feature of the overall transcriptional profile. It is possible that susceptible individuals exhibit a less pronounced detoxification response relative to insecticide resistant individuals or populations with a history of insecticide exposure, which may explain in part why our results differ from previous studies. For example, thiamethoxam resistant $A$. gossypii show heightened detoxification responses compared to susceptible individuals (Pan et al., 2015; Wu et al., 2018).

Finally, it is worthwhile to note that previous work reporting enhanced detoxification reponses in A. glycines used a targeted approach that measured expression of seven pre-selected genes with qRT-PCR (Xi et al., 2015), whereas the current study employed a global transcriptional approach using RNA-Seq. qRT-PCR based methods provide insight into differential expression of specific genes, which can be informative but biological relevance should be interpreted with caution. When viewed in the context of global transcriptional responses, our results demonstrate xenobiotic detoxification is part of a complex response involving many genes. RNA-Seq is useful for 
uncovering broader gene expression patterns that can be investigated in depth using focused or targeted studies that employ qRTPCR based methods.

Interestingly, we observed a dramatic burst of differential gene expression $12 \mathrm{~h}$ after exposure to insecticides that had largely subsided by $24 \mathrm{~h}$ post-exposure. Transcriptional spikes or "impulse responses" are a common phenomenon observed in many organisms in response to environmental stress or perturbations (Lopez-Maury et al., 2008; Yosef and Regev, 2011). For example, RNA-Seq studies have reported thousands of differentially expressed genes within a few hours of exposure to abiotic stressors in insects (Liu et al., 2017), plants (Lou et al., 2018) and fungi (Wang et al., 2017). Several studies also suggest stress-responsive genes are structured into distinct stages (e.g. early vs. late) and that transcriptional responses to various stressors become less pronounced over time (Bendjilali et al., 2017; Kawasaki et al., 2001; Sorensen et al., 2005). Widespread changes in gene expression that occur directly following exposure to stress are often transient and over time fine-tuned responses specific to the stressor are observed (Lopez- Maury et al., 2008). Our results suggest that the transcriptional stress response of $A$. glycines also potentially becomes more precise over time, which may help to balance physiological trade-offs with growth or reproduction, as prolonged stress responses can be energetically costly.

In conclusion, although our original hypothesis regarding enhanced detoxification under low-dose insecticide stress was not supported, our results suggest a complex process involving various metabolic pathways may be involved in A. glycines response to insecticides. Further research is needed to determine whether constitutive over-expression and/or induction of detoxification genes are the primary driver of observed insecticide resistance in North American populations of $A$. glycines.

Acknowledgments - The work reported here was supported by a grant awarded through the Life Sciences Competitive Grants Program at the University of NebraskaLincoln. Two anonymous reviewers, Sarjeet Gill, Rosanna Giordano and Ravi Kiran Donthu provided helpful comments on earlier drafts of the manuscript. 


\section{References}

Abdallah, I.S., Abou-Yousef, H.M., Fouad, E.A., Kandil, M.A.E.-H., 2016. The role of detoxifying enzymes in the resistance of the cowpea aphid (Aphis craccivora Koch) to thiamethoxam. J. Plant Prot. Res. 56, 67-72.

Bahadorani, S., Bahadorani, P., Phillips, J.P., Hilliker, A.J., 2008. The effects of vitamin supplementation on Drosophila life span under normoxia and under oxidative stress. J. Gerontol. Ser. A 63, 35-42. https://doi.org/10.1093/gerona/63.1.35

Bass, C., Puinean, A.M., Zimmer, C.T., Denholm, I., Field, L.M., Foster, S.P., Gutbrod, O., Nauen, R., Slater, R., Williamson, M.S., 2014. The evolution of insecticide resistance in the peach potato aphid, Myzus persicae. Insect Biochem. Mol. Biol. 51, 41-51.

Bendjilali, N., MacLeon, S., Kalra, G., Willis, S.D., Hossian, A.N., Avery, E., Wojtowicz, O., Hickman, M.J., 2017. Time-course analysis of gene expression during the Saccharomyces cerevisiae hypoxic response. G3 Genes Genomes Genet. 7, 221-231.

Benjamini, Y., Hochberg, Y., 1995. Controlling the false discovery rate: a practical and powerful approach to multiple testing. J. R. Stat. Soc. Ser. B Methodol. 57, 289-300.

Bolger, A.M., Lohse, M., Usadel, B., 2014. Trimmomatic: a flexible trimmer for Illumina sequence data. Bioinformatics 30, 2114-2120. https://doi.org/10.1093/ bioinformatics/btu170

Cabrera-Brandt, M., Silva, A.X., Le Trionnaire, G., Tagu, D., Figueroa, C.C., 2014. Transcriptomic responses of the aphid Myzus persicae nicotianae Blackman (Hemiptera: Aphididae) to insecticides: analyses in the single Chilean clone of the tobacco aphid. Chil. J. Agric. Res. 74, 191-199.

Carletto, J., Martin, T., Vanlerberghe-Masutti, F., Brevault, T., 2010. Insecticide resistance traits differ among and within host races in Aphis gossypii. Pest Manag. Sci. Former. Pestic. Sci. 66, 301-307.

Chandrasena, D., DiFonzo, C., Byrne, A., 2011. An aphid-dip bioassay to evaluate susceptibility of soybean aphid (Hemiptera: Aphididae) to pyrethroid, organophosphate, and neonicotinoid insecticides. J. Econ. Entomol. 104, 1357-1363.

Chiozza, M.V., O'Neal, M.E., Maclntosh, G.C., 2010. Constitutive and induced differential accumulation of amino acid in leaves of susceptible and resistant soybean plants in response to the soybean aphid (Hemiptera: Aphididae). Environ. Entomol. 39, 856-864.

Enders, L., Bickel, R., Brisson, J., Heng-Moss, T., Siegfried, B., Zera, A., Miller, N., 2014. Soybean aphid (Hemiptera: Aphididae) response to soybean plant defense: stress levels, tradeoffs, and cross-virulence. Environ. Entomol. 43, 47-57.

Enders, L.S., Miller, N.J., 2016. Aphid molecular stress biology. In: Vilcinskas, A. 
(Ed.), Biology and Ecology of Aphids. CRC Press, Boca Raton, Florida, USA, pp. 135-151.

Foster, S.P., Devine, G., Devonshire, A.L., 2007. Insecticide resistance. In: van Emden, H.F., Harrington, R. (Eds.), Aphids as Crop Pests. CABI, Wallingford, UK, pp. 261-268.

Hanson, A.A., Menger-Anderson, J., Silverstein, C., Potter, B.D., MacRae, I.V., Hodgson, E.W., Koch, R.L., 2017. Evidence for soybean aphid (Hemiptera: Aphididae) resistance to pyrethroid insecticides in the upper Midwestern United States. J. Econ. Entomol. 110, 2235-2246.

Kawasaki, S., Borchert, C., Deyholos, M., Wang, H., Brazille, S., Kawai, K., Galbraith, D., Bohnert, H.J., 2001. Gene expression profiles during the initial phase of salt stress in rice. Plant Cell 13, 889-905.

Kim, D., Langmead, B., Salzberg, S.L., 2015. HISAT: a fast spliced aligner with low memory requirements. Nat. Methods 12, 357-360. https://doi.org/10.1038/ nmeth.3317

Kim, H., Kim, M.Y., Kim, K.S., Lee, H., Hoelmer, K., Lee, S., 2010. Isolation and characterization of microsatellite loci from the soybean aphid, Aphis glycines Matsumura (Hemiptera: Aphididae). Mol. Ecol. 10, 1098-1105.

Koch, R.L., Hodgson, E.W., Knodel, J.J., Varenhorst, A.J., Potter, B.D., 2018. Management of insecticide-resistant soybean aphids in the upper Midwest of the United States. J. Integr. Pest Manag. 9, 23.

Liao, Y., Smyth, G.K., Shi, W., 2014. featureCounts: an efficient general purpose program for assigning sequence reads to genomic features. Bioinformatics 30 , 923-930. https://doi.org/10.1093/bioinformatics/btt656

Liu, Y., Su, H., Li, R., Li, X., Xu, Y., Dai, X., Zhou, Y., Wang, H., 2017. Comparative transcriptome analysis of Glyphodes pyloalis Walker (Lepidoptera: Pyralidae) reveals novel insights into heat stress tolerance in insects. BMC Genomics 18. https://doi.org/10.1186/s12864-017-4355-5

Lopez-Maury, L., Marguerat, S., Bahler, J., 2008. Tuning gene expression to changing environments: from rapid responses to evolutionary adaptation. Nat. Rev. Genet. 9, 583-593. https://doi.org/10.1038/nrg2398.

Lou, X., Wang, H., Ni, X., Gao, Z., Iqbal, S., 2018. Integrating proteomic and transcriptomic analyses of loquat (Eriobotrya japonica Lindl.) in response to cold stress. Gene 677, 57-65. https://doi.org/10.1016/j.gene.2018.07.022

Love, M.I., Huber, W., Anders, S., 2014. Moderated estimation of fold change and dispersion for RNA-seq data with DESeq2. Genome Biol. 15, 550. https://doi. org/10.1186/s13059-014- 0550-8.

Magalhaes, L.C., Hunt, T.E., Siegfried, B.D., 2008. Development of methods to evaluate susceptibility of soybean aphid to imidacloprid and thiamethoxam at lethal and sublethal concentrations. Entomol. Exp. Appl. 128, 330-336.

Michel, A.P., Zhang, W., Kyo Jung, J., Kang, S.-T., Rouf Mian, M.A., 2009. Crossspecies amplification and polymorphism of microsatellite loci in the soybean aphid, Aphis glycines. J. Econ. Entomol. 102, 1389-1392.

Nauen, R., Elbert, A., McCaffery, A., Slater, R., Sparks, T.C., 2011. IRAC: insecticide 
resistance, and mode of action classification of insecticides. Mod. Crop Prot. Compd. 935-955.

Pan, Y., Peng, T., Gao, X., Zhang, L., Yang, C., Xi, J., Xin, X., Bi, R., Shang, Q., 2015. Transcriptomic comparison of thiamethoxam-resistance adaptation in resistant and susceptible strains of Aphis gossypii Glover. Comp. Biochem. Physiol. Genom. Proteonom. 13, 10-15.

Pierson, L.M., Heng-Moss, T.M., Hunt, T.E., Reese, J.C., 2010. Categorizing the resistance of soybean genotypes to the soybean aphid (Hemiptera: Aphididae). J. Econ. Entomol. 103, 1405-1411.

Silva, A.X., Jander, G., Samaniego, H., Ramsey, J.S., Figueroa, C.C., 2012. Insecticide resistance mechanisms in the green peach aphid Myzus persicae (Hemiptera: Aphididae) I: a transcriptomic survey. PLoS One 7, e36366. https://doi. org/10.1371/journal.pone.0036366

Sorensen, J.G., Nielsen, M.M., Kruhoffer, M., Justesen, J., Loeschcke, V., 2005. Full genome gene expression analysis of the heat stress response in Drosophila melanogaster. Cell Stress Chaperones 10, 312.

Wang, D., Li, L., Wu, G., Vasseur, L., Yang, G., Huang, P., 2017. De novo transcriptome sequencing of Isaria cateniannulata and comparative analysis of gene expression in response to heat and cold stresses. PLoS One 12, e0186040. https://doi.org/10.1371/journal.pone.0186040

Wang, K., Zhang, M., Huang, Y., Yang, Z., Su, S., Chen, M., 2018. Characterisation of imidacloprid resistance in the bird cherry-oat aphid, Rhopalosiphum padi, a serious pest on wheat crops. Pest Manag. Sci. 74, 1457-1465.

Wu, Y., Xu, H., Pan, Y., Gao, X., Xi, J., Zhang, J., Shang, Q., 2018. Expression profile changes of cytochrome P450 genes between thiamethoxam susceptible and resistant strains of Aphis gossypii Glover. Pestic. Biochem. Physiol.

Xi, J., Pan, Y., Bi, R., Gao, X., Chen, X., Peng, T., Zhang, M., Zhang, H., Hu, X., Shang, Q., 2015. Elevated expression of esterase and cytochrome $\mathrm{P} 450$ are related with lambda-cyhalothrin resistance and lead to cross resistance in Aphis glycines Matsumura. Pestic. Biochem. Physiol. 118, 77-81.

Yosef, N., Regev, A., 2011. Impulse control: temporal dynamics in gene transcription. Cell 144, 886-896. https://doi.org/10.1016/j.cell.2011.02.015

Young, M.D., Wakefield, M.J., Smyth, G.K., Oshlack, A., 2010. Gene ontology analysis for RNAseq: accounting for selection bias. Genome Biol. 11, R14. https://doi.org/10.1186/gb-2010-11-2-r14

Yu, S.J., 2011. The Toxicology and Biochemistry of Insecticides. CRC Press, Boca Raton, Florida, USA. https://doi.org/10.1201/9781420059762

Appendix A. Supplementary data - Supplementary data to this article follows:

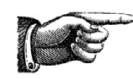




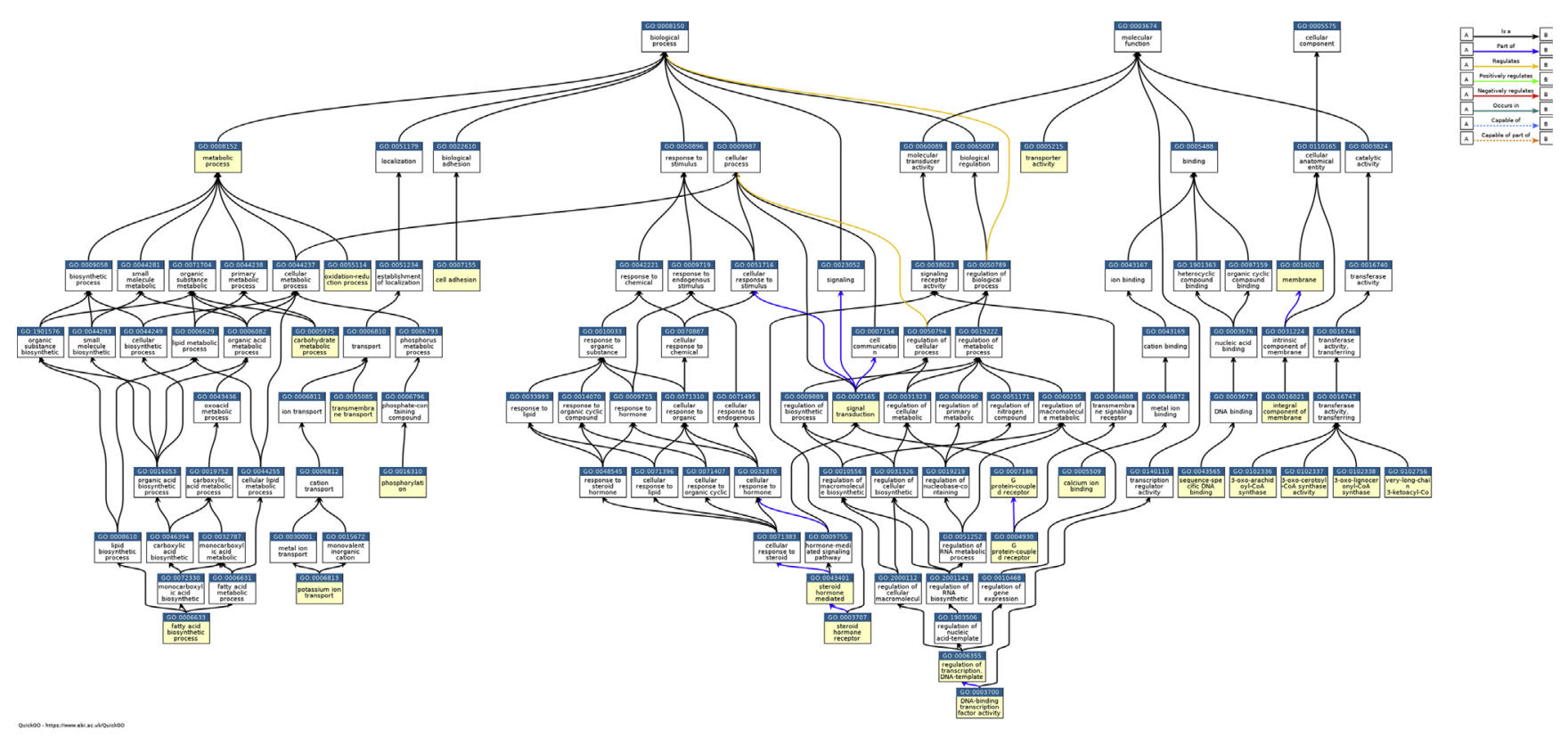

Fig S1. Ancestor chart of overrepresented GO terms associated with genes up-regulated 12 hours after exposure to esfenvalerate.

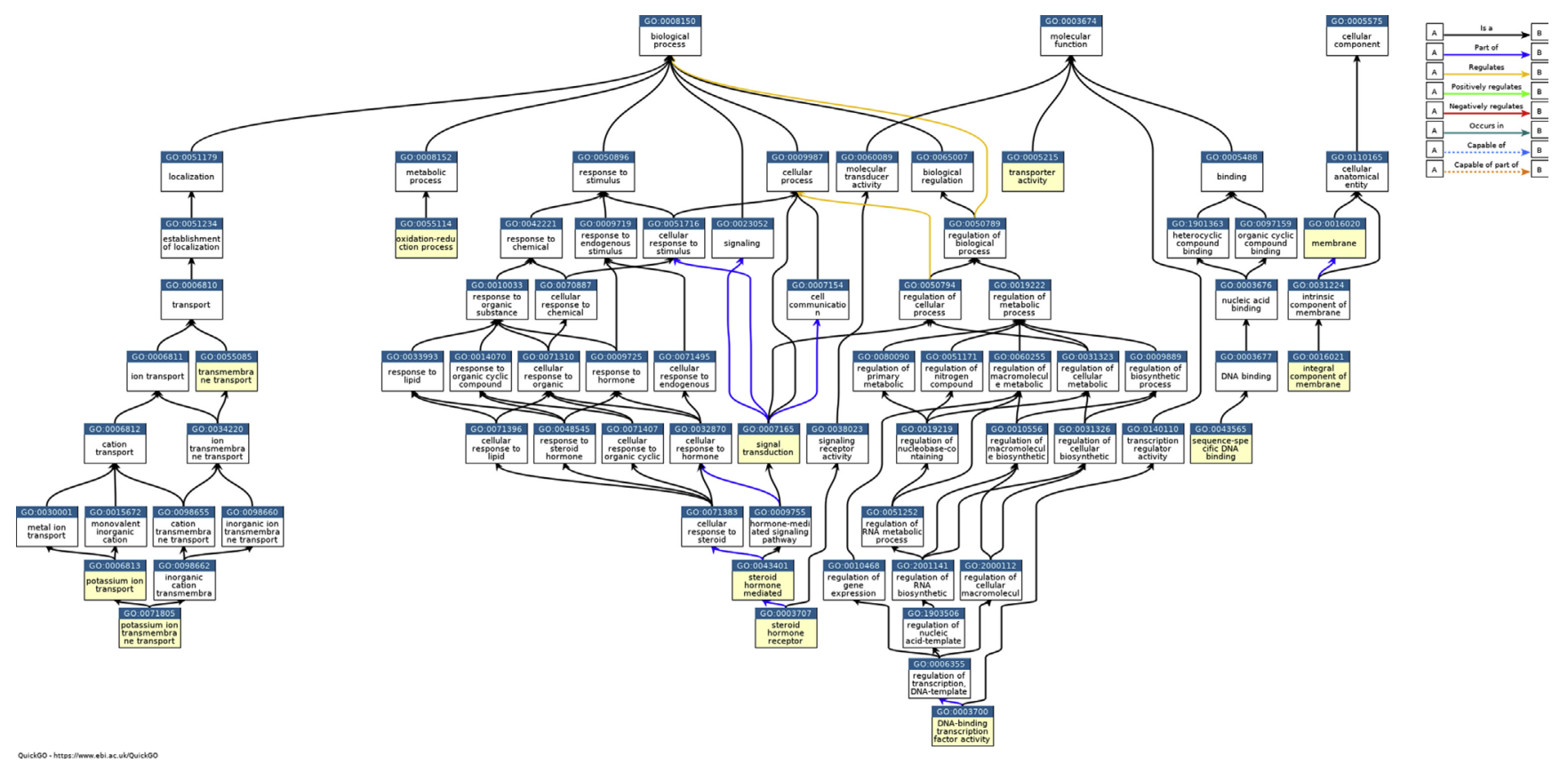

Fig S2. Ancestor chart of overrepresented GO terms associated with genes up-regulated 12 hours after exposure to thiamethoxam. 


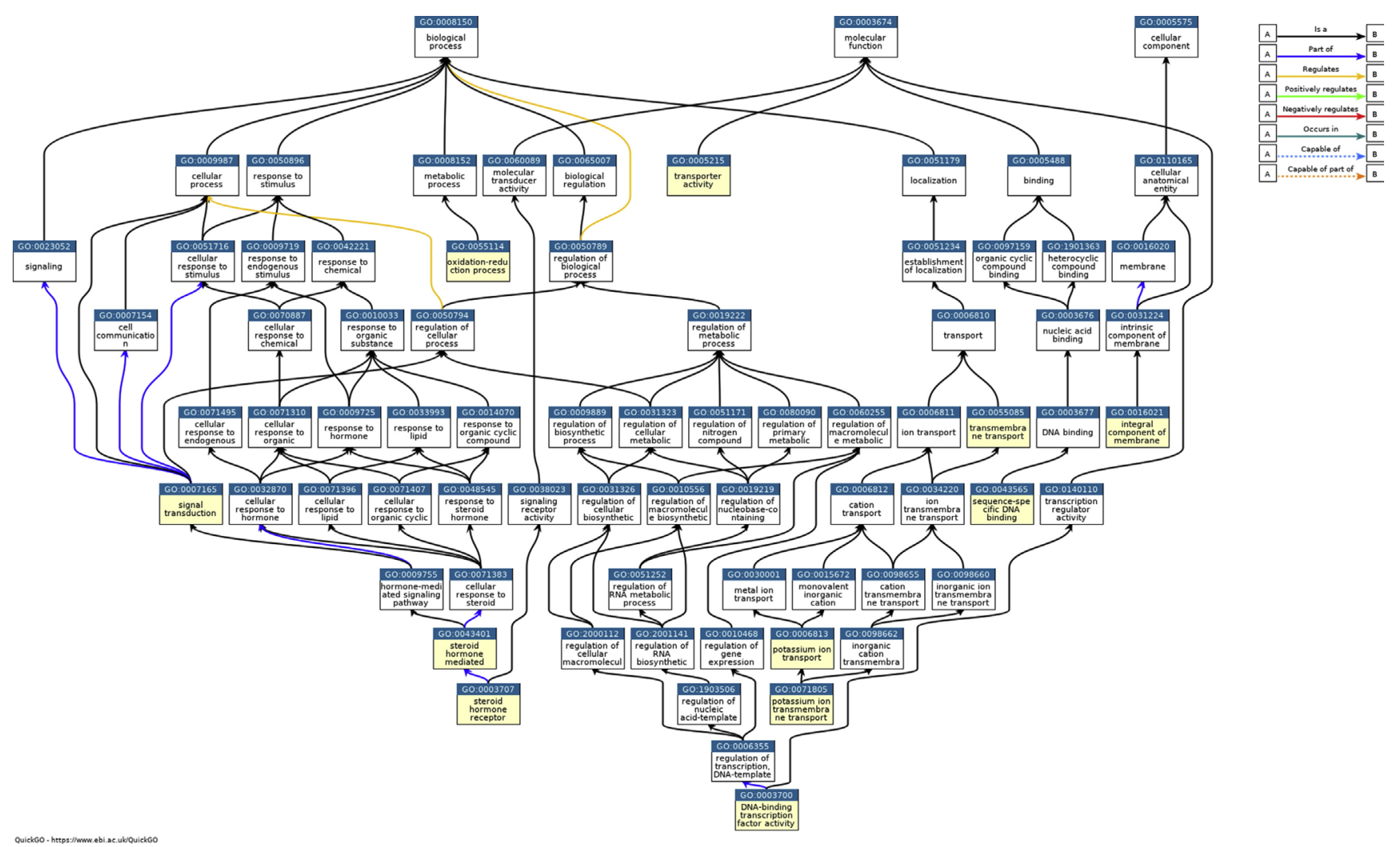

Fig S3. Ancestor chart of overrepresented GO terms associated with genes upregulated 12 hours after exposure to esfenvalerate and 12 hours after exposure to thiamethoxam.

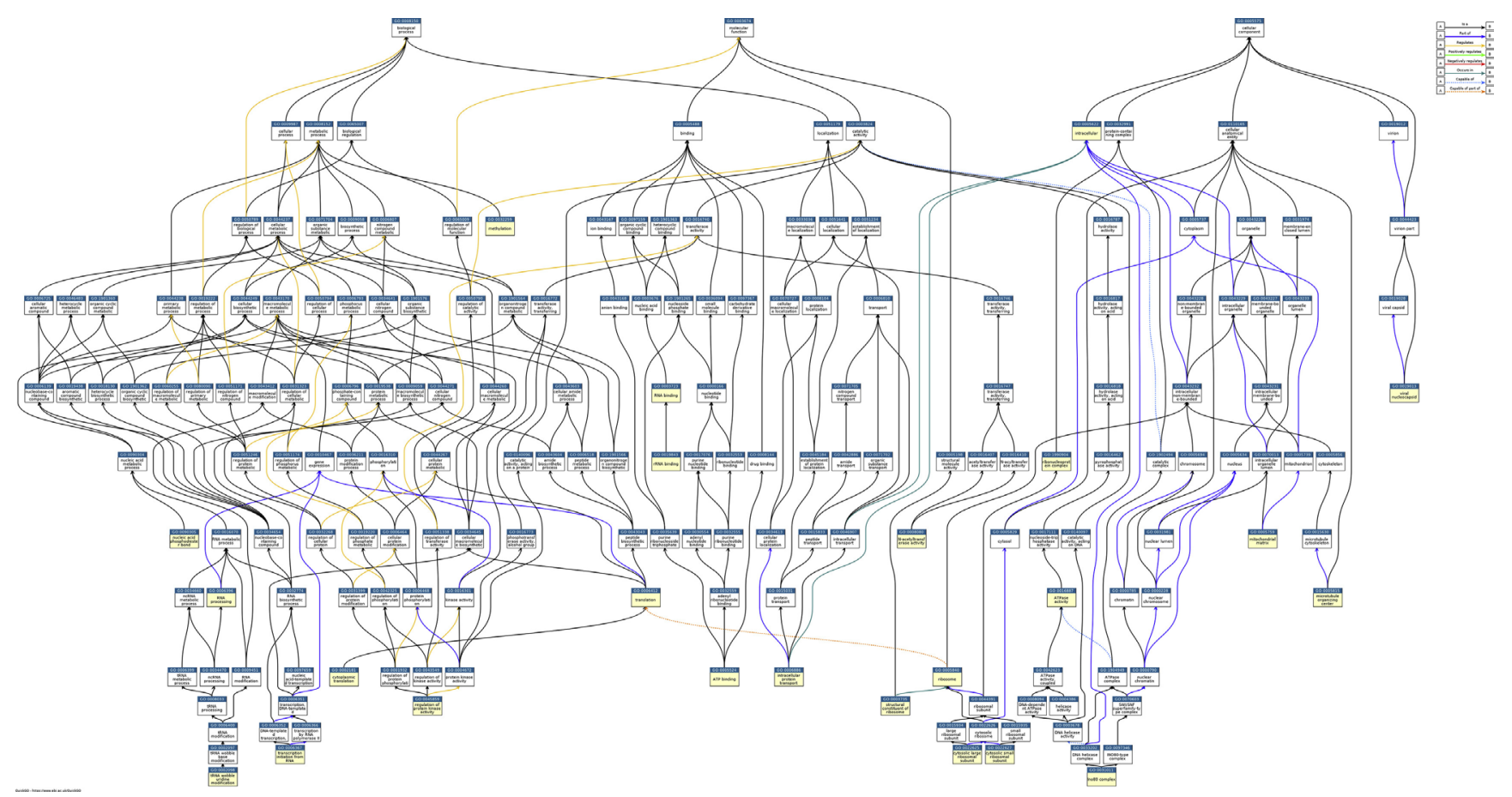

Fig S4. Ancestor chart of overrepresented GO terms associated with genes downregulated 12 hours after exposure to esfenvalerate. 

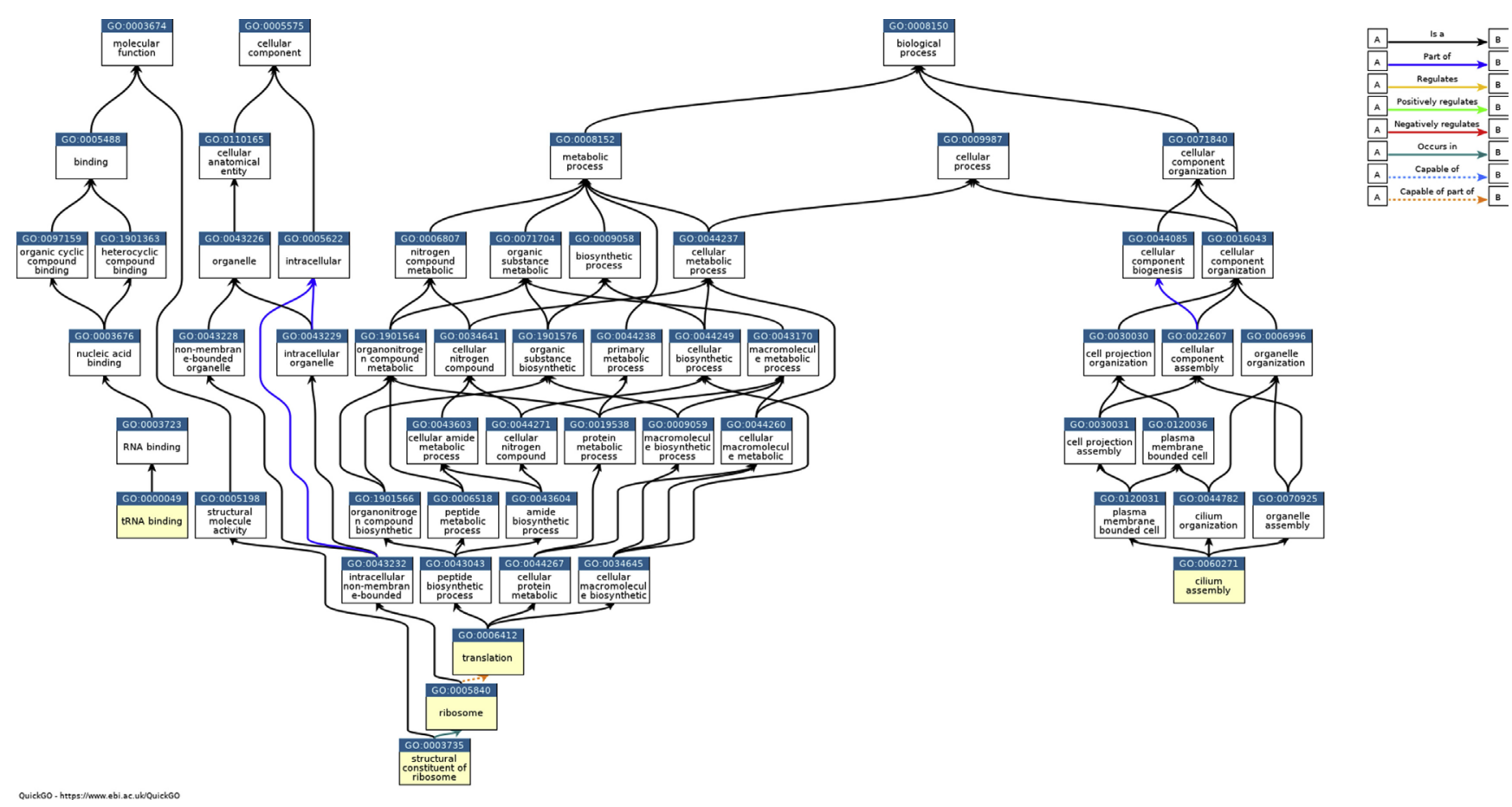

Fig S5. Ancestor chart of overrepresented GO terms associated with genes downregulated 12 hours after exposure to thiamethoxam.
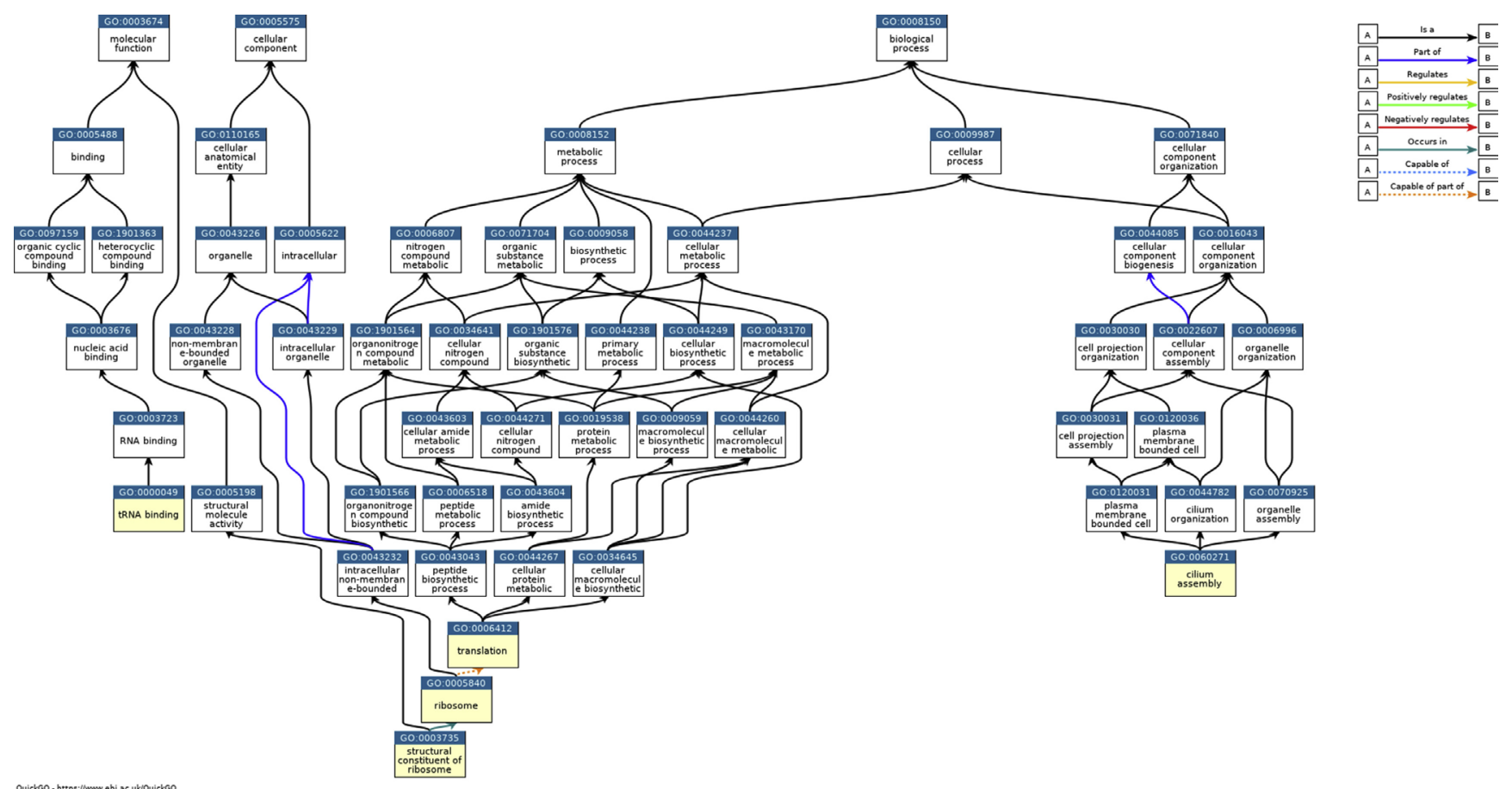

Fig S6. Ancestor chart of overrepresented GO terms associated with genes downregulated 12 hours after exposure to esfenvalerate and 12 hours after exposure to thiamethoxam. 
Supplemental Table S1. Inferred functions of the 20 most strongly up-regulated genes (relative to control) $12 \mathrm{~h}$ after exposure to esfenvalerate.

\begin{tabular}{|l|l|}
\hline AG6014660 & $\begin{array}{l}\text { Putative hexokinase. GO terms suggest possible role in glycolysis or glucose } \\
\text { homeostasis. Maybe involved in energy metabolism, often seen as a common part of } \\
\text { general stress response. Also strongly upregulated in response to thiamethoxam at 12h. }\end{array}$ \\
\hline AG6034535 & GO terms suggest membrane protein, possibly interacts with steroids?. Function unclear. \\
\hline AG6026920 & $\begin{array}{l}\text { Putatively involved in alpha-tocopherol (vitamin E) transport. Alpha-tocopherol helps } \\
\text { protect against oxidative stress in Drosophila, maybe general stress response. }\end{array}$ \\
\hline AG6025731 & Unknown. \\
\hline AG6025720 & IPS indicates a transmembrane protein, otherwise unknown. \\
\hline AG6004183 & Unknown \\
\hline AG6029987 & Probably a membrane protein, otherwise unknown. \\
\hline AG6020723 & Unknown \\
\hline AG6031115 & Unknown, B2G GO term suggests a DNA binding protein. \\
\hline AG6022723 & Unknown \\
\hline AG6026921 & $\begin{array}{l}\text { Possibly involved in alpha tocopherol transport. *NOTE* Gene number is sequential with } \\
\text { AG6026920, The two are adjacent in the genome. Blastx suggests 2 parts of the same } \\
\text { gene. }\end{array}$ \\
\hline AG6005892 & Unknown. \\
\hline AG6025759 & Unknown. \\
\hline AG6021535 & Membrane-bound alkaline phosphatase. \\
\hline AG6027850 & $\begin{array}{l}\text { The blast2Go "name" and interpro scan indicate tropomyosin, involved in muscle } \\
\text { contraction. Blast2GO GO terms also include "nucleic acid binding" and "alanine-tRNA } \\
\text { ligase activity". Also strongly upregulated in response to thiamethoxam at 12h. }\end{array}$ \\
\hline AG6013434 & Unknown. \\
\hline AG6023616 & $\begin{array}{l}\text { Unclear, B2G GO terms hint at both nucleic acid binding and myosin complex / motor } \\
\text { function. }\end{array}$ \\
\hline AG6032677 & Membrane protein. Possibly involved in G-protein based signaling. \\
\hline Unknown. \\
\hline Possible membrane-bound glycosyl hydrolase. \\
\hline
\end{tabular}


Supplemental Table S2. Inferred functions of the 20 most strongly up-regulated genes (relative to control) $12 \mathrm{~h}$ after exposure to thiamethoxam.

\begin{tabular}{|c|c|}
\hline AG6034535 & Unidentified membrane protein \\
\hline AG6014660 & $\begin{array}{l}\text { Putative hexokinase. GO terms suggest possible role in glycolysis or glucose } \\
\text { homeostasis. Maybe involved in energy metabolism, often seen as a common part of } \\
\text { general stress response. Also strongly upregulated in response to esfenvalerate at } 12 \mathrm{~h} \text {. }\end{array}$ \\
\hline AG6013188 & Unidentified transmembrane protein. \\
\hline AG6029987 & Unknown. \\
\hline AG6013778 & Unknown. \\
\hline AG6010228 & $\begin{array}{l}\text { GO terms indicate 1) hydrolysis of glycosidic bonds and/or glucose dehydrogenase } \\
\text { activity, 2) FAD binding (a quick search on web of science indicates that FAD-dependent } \\
\text { glucose dehydrogenases exist, although they mostly seem to have been isolated from } \\
\text { fungi), 3) membrane protein, 4) structural constituent of cuticle. No obvious function, but } \\
\text { could point to something in the integument, possibly involved in chitin metabolism / } \\
\text { remodeling. }\end{array}$ \\
\hline AG6022723 & Unknown. \\
\hline AG6031274 & Unknown. \\
\hline AG6031274 & Unknown. \\
\hline AG6027850 & $\begin{array}{l}\text { The blast2Go "name" and interpro scan indicate tropomyosin, involved in muscle } \\
\text { contraction. Blast2GO GO terms also include "nucleic acid binding" and "alanine-tRNA } \\
\text { ligase activity". Also strongly upregulated in response to esfenvalerate at } 12 \mathrm{~h} \text {. }\end{array}$ \\
\hline AG6008644 & Unknown. \\
\hline AG6020826 & Unknown. \\
\hline AG6034507 & Probable membrane-bound Ras protein involved in GTP-mediated signal transduction. \\
\hline AG6023670 & Unknown. \\
\hline AG6025517 & Unknown. \\
\hline AG6004602 & $\begin{array}{l}\text { Kiran Donthu's B2G GO terms are a mixed bag, membrane component, zinc ion binding, } \\
\text { and DNA integration (ie.integration of one DNA molecule into another). Not obvious what } \\
\text { this might be. }\end{array}$ \\
\hline AG6032677 & Probable membrane-bound Ras protein involved in GTP-mediated signal transduction. \\
\hline AG6032370 & $\begin{array}{l}\text { Kiran Donthu's B2G GO terms point to both nucleic acid binding and endopeptidase } \\
\text { activities. Not at all sure what to make of that. }\end{array}$ \\
\hline AG6018719 & Probable transcription factor. \\
\hline AG6036254 & Unknown. \\
\hline
\end{tabular}


Supplemental Table S3. Inferred functions of the 20 most strongly down-regulated genes (relative to control) $12 \mathrm{~h}$ after exposure to esfenvalerate.

\begin{tabular}{|l|l|}
\hline AG6026208 & Metallopeptidase, possibly membrane-bound. \\
\hline AG6028839 & Unknown. \\
\hline AG6000779 & Unidentified transmembrane protein. \\
\hline AG6029001 & Unknown. \\
\hline AG6039807 & Unknown. \\
\hline AG6039777 & Unknown. \\
\hline AG6036823 & Unknown. \\
\hline AG6007025 & Unidentified membrane protein. \\
\hline AG6023047 & Unknown. \\
\hline AG6023137 & Unknown. \\
\hline AG6041832 & Unknown. \\
\hline AG6004421 & Unknown. \\
\hline AG6042054 & Unknown. \\
\hline AG6021652 & Unknown. \\
\hline AG6002463 & Unknown. \\
\hline AG6042240 & Unknown. \\
\hline AG6021895 & Unknown. \\
\hline AG6003346 & Unknown. \\
\hline AG6012178 & Unknown. \\
\hline
\end{tabular}


Supplemental Table S4. Inferred functions of the 20 most strongly down-regulated genes (relative to control) $12 \mathrm{~h}$ after exposure to thiamethoxam.

\begin{tabular}{|l|l|}
\hline AG6007487 & Unknown. \\
\hline AG6039732 & Unknown. \\
\hline AG6015398 & Unidentified transmembrane protein. \\
\hline AG6019493 & Unknown. \\
\hline AG6023047 & Unknown. \\
\hline AG6041137 & Unknown. \\
\hline AG6039777 & Unknown. \\
\hline AG6040592 & Unknown. \\
\hline AG6003610 & Unknown. \\
\hline AG6041833 & Unknown. \\
\hline AG6037173 & Unknown. \\
\hline AG6028214 & Unknown. \\
\hline AG6029325 & Unknown. \\
\hline AG6013956 & Unknown. \\
\hline AG6025557 & Unknown. \\
\hline AG6019953 & Unidentified transmembrane protein. \\
\hline AG6005035 & Unknown. \\
\hline AG6041257 & Unknown. \\
\hline AG6025708 & Unknown. \\
\hline AG6003610 & Unknown. \\
\hline
\end{tabular}


Supplemental Table S5. Inferred functions of the 20 most strongly up-regulated genes (relative to control) $24 \mathrm{~h}$ after exposure to esfenvalerate.

\begin{tabular}{|l|l|}
\hline AG6035448 & Unknown. \\
\hline AG6015336 & B2G GO terms suggest lipid binding/transport. \\
\hline AG6001561 & $\begin{array}{l}\text { B2G terms seem a bit inconsistent, pointing to either FAD-dependent oxidoreductase } \\
\text { *or neuropeptide signalling. The latter is supported by IPS annotating as a pyrokinin, } \\
\text { a family of insect neuropeptides that mediate visercal muscle contractions. }\end{array}$ \\
\hline AG6006453 & $\begin{array}{l}\text { IPS finds fibronectin type III / immunoglobulin-like fold domain and an epidermal } \\
\text { growth factor-like domain. These are found in a wide range of proteins so the function } \\
\text { is unclear, possibly cell adhesion. }\end{array}$ \\
\hline AG6025377 & Probable transcription factor. \\
\hline AG6025439 & $\begin{array}{l}\text { Looks like a member of the SMP-30/regulacin family. These proteins regulate cellular } \\
\text { Ca }{ }^{2+}, \text { could be involved in signaling but this is a big family with a wide variety of } \\
\text { functions. }\end{array}$ \\
\hline AG6025438 & Probably a membrane-bound endopeptidase. \\
\hline AG6024969 & Unknown. \\
\hline AG6015929 & $\begin{array}{l}\text { B2G GO terms point to heterocyclic compound binding. A lot of proteins associated } \\
\text { with this GO term bind nucleotides or nucleic acids. Could be a transcription factor or } \\
\text { other transcriptional regulator (supported by the b2g "name" being af4 fmr2 family } \\
\text { member 4-like). }\end{array}$ \\
\hline AG6035449 & Possible membrane-bound protease. \\
\hline AG6028764 & Unknown. \\
\hline AG6020067 & Putative glucuronidation involved in phase II xenobiotic metabolism. \\
\hline AG6006634 & Unknown. \\
\hline AG6013434 & Unknown. \\
\hline AG6008259 & Probable actin-binding protein. \\
\hline AG6008259 & Membrane protein, possibly an acyl transferase. \\
\hline AG6013625 & Unknown. \\
\hline AG6013554 & Transcription factor. \\
\hline AG6018859 & Unidentified transmembrane protein. \\
\hline & Unknown. \\
\hline
\end{tabular}


Supplemental Table S6. Inferred functions of the 20 most strongly down-regulated genes (relative to control) $24 \mathrm{~h}$ after exposure to esfenvalerate.

\begin{tabular}{|l|l|}
\hline AG6010560 & Unknown. \\
\hline AG6010580 & Unknown. \\
\hline AG6010557 & Unknown. \\
\hline AG6008446 & $\begin{array}{l}\text { Possible protein kinase, maybe membrane-bound. This could just be a coincidence, but the } \\
\text { p2G name "repetitive proline-rich cell wall protein 2" matches a Uniprot entry for a soybean } \\
\text { protein! }\end{array}$ \\
\hline AG6010559 & Unknown. \\
\hline AG6010564 & Unidentified membrane protein. \\
\hline AG6010562 & Unknown. \\
\hline AG6019022 & Unknown. \\
\hline AG6039736 & Mitochondrial NADH dehydrogenase, part of ATP synthesis. \\
\hline AG6014330 & Unidentified membrane protein. \\
\hline AG6010558 & Unknown. \\
\hline AG6015086 & Unknown. \\
\hline AG6029798 & Unidentified membrane protein. \\
\hline AG6029798 & $\begin{array}{l}\text { Transmembrane sugar transporter. B2G also gives a couple of GO terms related to } \\
\text { processing small nuclear RNAs, which seems contradictory. }\end{array}$ \\
\hline AG6003000 & Possible cytochrome P450 monoxygenase. \\
\hline AG6009434 & Cuticle protein. \\
\hline AG6025422 & Unidentified membrane protein. \\
\hline AG6006591 & Unknown. \\
\hline AG6002747 & Peroxidase. \\
\hline
\end{tabular}


Supplemental Table S7. Expression levels of putative cytochrome P450 monooxygenase genes, relative to controls ( $\log _{2}$ fold-change). Asterisks indicate significant differential expression at a false-discovery rate of 0.1 . "NA" indicates gene expression too low to be measured in either control or treatment conditions.

\begin{tabular}{|c|c|c|c|c|}
\hline Gene & Esfenvalerate, $12 \mathrm{~h}$ & Esfenvalerate, $24 \mathrm{~h}$ & Thiamethoxam, 12h & Thiamethoxam, 24h \\
\hline AG6008728 & 0.534 & 0.173 & 0.561 & -0.057 \\
\hline AG6018178 & $1.301^{*}$ & 0.065 & 0.981 & -0.018 \\
\hline AG6036432 & -0.309 & 0.012 & -0.122 & -0.034 \\
\hline AG6027734 & $1.309^{*}$ & 0.034 & $1.141^{*}$ & -0.1 \\
\hline AG6030583 & $0.673^{*}$ & 0.266 & 0.512 & -0.053 \\
\hline AG6027735 & $0.816^{*}$ & -0.004 & 0.348 & -0.053 \\
\hline AG6026478 & 0.137 & 0.086 & 0.204 & -0.118 \\
\hline AG6002505 & 0.384 & 0.117 & 0.409 & -0.043 \\
\hline AG6019116 & $0.535^{*}$ & $0.535^{*}$ & 0.313 & -0.028 \\
\hline AG6014576 & $-0.793^{*}$ & 0.292 & $-0.898^{*}$ & -0.137 \\
\hline AG6013195 & $-0.884^{*}$ & -0.012 & -0.43 & 0.125 \\
\hline AG6030586 & $0.624^{*}$ & 0.409 & 0.375 & -0.081 \\
\hline AG6018153 & 0.711 & 0.13 & 0.615 & -0.044 \\
\hline AG6004782 & -0.21 & 0.13 & -0.202 & 0.056 \\
\hline AG6018487 & $0.697^{\star}$ & 0.333 & -0.203 & -0.048 \\
\hline AG6002506 & -0.25 & -0.371 & -0.503 & 0.039 \\
\hline AG6026424 & $0.409^{*}$ & 0.057 & $0.317^{*}$ & -0.121 \\
\hline AG6018923 & $1.357^{\star}$ & $0.636^{*}$ & $0.662^{*}$ & 0.055 \\
\hline AG6000572 & $-0.754^{*}$ & 0.083 & -0.519 & 0.05 \\
\hline AG6011084 & NA & 0.052 & 0.006 & -0.04 \\
\hline AG6030591 & -0.401 & -0.031 & -0.494 & 0.118 \\
\hline AG6014305 & -0.111 & 0.332 & -0.053 & 0.105 \\
\hline AG6023746 & $1.413^{*}$ & $0.624^{*}$ & $0.723^{*}$ & -0.011 \\
\hline AG6011346 & -0.058 & 0.231 & -0.112 & -0.137 \\
\hline AG6035846 & $1.32^{*}$ & 0.057 & $0.948^{\star}$ & -0.096 \\
\hline AG6012485 & $1.105^{\star}$ & 0.214 & $0.65^{*}$ & -0.094 \\
\hline AG6022965 & -0.368 & 0.208 & 0.155 & 0.028 \\
\hline AG6035848 & $1.231^{*}$ & $0.578^{*}$ & 0.303 & -0.076 \\
\hline
\end{tabular}


Supplemental Table S7, continued.

\begin{tabular}{|c|c|c|c|c|}
\hline AG6011050 & $-0.607^{\star}$ & -0.17 & -0.303 & -0.013 \\
\hline AG6034428 & 0.672 & 0.389 & $0.752^{*}$ & 0.07 \\
\hline AG6003000 & 0.394 & $-0.638^{*}$ & 0.547 & -0.225 \\
\hline AG6003479 & 0.303 & 0.135 & -0.263 & 0.069 \\
\hline AG6036333 & $1.835^{*}$ & 0.201 & $0.812^{*}$ & -0.011 \\
\hline AG6006129 & $-0.662^{*}$ & -0.269 & $-0.468^{*}$ & 0.043 \\
\hline AG6016439 & $1.496^{*}$ & 0.428 & 0.613 & 0.058 \\
\hline AG6036334 & $1.005^{*}$ & 0.116 & $0.671^{*}$ & -0.115 \\
\hline AG6002794 & 0.554 & 0.221 & 0.574 & 0.048 \\
\hline AG6023846 & -0.031 & 0.078 & -0.241 & 0.045 \\
\hline AG6002795 & 0.468 & 0.117 & 0.245 & -0.087 \\
\hline AG6001356 & -0.263 & 0.1 & 0.072 & -0.002 \\
\hline AG6018477 & $1.087^{*}$ & 0.403 & $0.706^{*}$ & 0.002 \\
\hline AG6005201 & $0.813^{*}$ & 0.223 & $0.686^{*}$ & -0.035 \\
\hline AG6018927 & 0.391 & 0.191 & 0.055 & -0.086 \\
\hline AG6000576 & $0.799^{*}$ & 0.473 & $0.811^{*}$ & -0.09 \\
\hline AG6005202 & $-0.668^{*}$ & -0.156 & -0.456 & -0.067 \\
\hline AG6030787 & $0.988^{*}$ & 0.079 & 0.717 & 0.026 \\
\hline AG6018478 & -0.22 & -0.01 & -0.058 & -0.038 \\
\hline AG6001358 & $-0.48^{\star}$ & -0.183 & -0.365 & -0.067 \\
\hline AG6019229 & 0.549 & 0.256 & 0.233 & -0.074 \\
\hline AG6036430 & $0.95^{\star}$ & -0.247 & $0.677^{*}$ & -0.068 \\
\hline AG6018481 & $0.878^{*}$ & 0.31 & 0.449 & -0.031 \\
\hline AG6019231 & $1.488^{*}$ & 0.509 & $0.839^{\star}$ & 0.034 \\
\hline AG6018931 & -0.191 & 0.082 & -0.105 & -0.032 \\
\hline AG6039218 & 0.363 & -0.041 & 0.141 & -0.044 \\
\hline
\end{tabular}


Supplemental Table S8. Expression levels of putative glutathione-S-transferase genes, relative to controls ( $\log _{2}$ fold-change). Asterisks indicate significant differential expression at a falsediscovery rate of 0.1 .

\begin{tabular}{|l|r|r|r|r|}
\hline Gene & Esfenvalerate, $12 \mathrm{~h}$ & Esfenvalerate, $24 \mathrm{~h}$ & Thiamethoxam, $12 \mathrm{~h}$ & Thiamethoxam, 24h \\
\hline AG6027400 & -0.361 & -0.133 & -0.115 & 0.045 \\
\hline AG6022120 & 0.374 & -0.079 & 0.323 & -0.05 \\
\hline AG6022314 & $-0.195^{*}$ & 0 & -0.118 & 0.074 \\
\hline AG6025610 & -0.164 & -0.174 & -0.126 & -0.125 \\
\hline AG6018942 & -0.221 & -0.243 & -0.057 & -0.076 \\
\hline AG6013975 & 0.07 & -0.059 & 0.078 & 0.027 \\
\hline AG6018943 & $0.941^{*}$ & 0.155 & 0.582 & -0.074 \\
\hline AG6003443 & $0.443^{*}$ & 0.02 & $0.451^{*}$ & -0.043 \\
\hline AG6024616 & -0.023 & 0.031 & -0.123 & -0.085 \\
\hline AG6011298 & $-0.392^{*}$ & -0.231 & -0.248 & -0.193 \\
\hline AG6024617 & $1.09^{*}$ & -0.198 & $0.761^{*}$ & -0.124 \\
\hline AG6011300 & -0.05 & 0.027 & 0.219 & -0.147 \\
\hline AG6021936 & 0.102 & -0.022 & 0.02 & -0.091 \\
\hline AG6003576 & 0.078 & 0.03 & -0.066 & -0.111 \\
\hline AG6013069 & $-0.323^{*}$ & -0.181 & -0.231 & 0.032 \\
\hline
\end{tabular}


Supplemental Table S9. Expression levels of putative carboxylesterase genes, relative to controls ( $\log _{2}$ fold-change). Asterisks indicate significant differential expression at a falsediscovery rate of 0.1 .

\begin{tabular}{|c|c|c|c|c|}
\hline Gene & Esfenvalerate, $12 \mathrm{~h}$ & Esfenvalerate, $24 \mathrm{~h}$ & Thiamethoxam, 12h & Thiamethoxam, 24h \\
\hline AG6004867 & $0.64^{*}$ & -0.227 & $0.867^{\star}$ & -0.091 \\
\hline AG6032899 & $1.399^{*}$ & 0.392 & $1.02^{*}$ & 0.022 \\
\hline AG6010355 & $-0.541^{*}$ & -0.222 & -0.139 & -0.041 \\
\hline AG6032900 & 0.458 & 0.133 & 0.128 & -0.068 \\
\hline AG6010358 & -0.168 & 0.212 & -0.2 & 0.149 \\
\hline AG6007844 & $-0.441^{*}$ & -0.338 & -0.092 & 0.005 \\
\hline AG6007846 & $-0.447^{*}$ & -0.036 & -0.239 & 0.069 \\
\hline AG6033369 & 0.084 & -0.127 & 0.158 & -0.07 \\
\hline AG6002269 & -0.137 & 0.017 & -0.087 & -0.082 \\
\hline AG6015193 & $0.809^{*}$ & 0.252 & $0.493^{*}$ & -0.052 \\
\hline AG6015032 & 0.432 & 0.257 & 0.132 & -0.005 \\
\hline AG6007848 & $0.737^{*}$ & 0.194 & 0.52 & -0.007 \\
\hline AG6002272 & 0.42 & 0.155 & -0.126 & -0.032 \\
\hline AG6023925 & 0.522 & 0.288 & 0.338 & 0.034 \\
\hline AG6007850 & $-0.473^{*}$ & -0.444 & 0.008 & -0.054 \\
\hline AG6007582 & $1.176^{\star}$ & 0.205 & $1.001^{*}$ & -0.038 \\
\hline AG6023928 & 0.523 & 0.297 & 0.188 & 0 \\
\hline AG6023929 & 0.484 & 0.147 & 0.142 & -0.003 \\
\hline AG6023930 & $1.102^{*}$ & 0.147 & 0.661 & 0.021 \\
\hline AG6023931 & $0.684^{*}$ & 0.435 & 0.326 & 0.126 \\
\hline AG6015464 & 0.008 & 0.05 & -0.021 & -0.087 \\
\hline AG6025282 & $0.47^{*}$ & 0.021 & 0.311 & -0.201 \\
\hline AG6015465 & $-0.392^{*}$ & -0.221 & -0.277 & -0.049 \\
\hline AG6011356 & 0.133 & 0.262 & 0.028 & 0.034 \\
\hline AG6016049 & -0.066 & -0.334 & 0.096 & -0.11 \\
\hline AG6015196 & 0.018 & 0.037 & 0.165 & -0.024 \\
\hline AG6025283 & $0.898^{*}$ & 0.093 & 0.194 & -0.083 \\
\hline AG6016051 & 0.552 & -0.031 & 0.445 & -0.042 \\
\hline AG6008253 & $-1.04^{*}$ & -0.254 & $-0.57^{\star}$ & 0.049 \\
\hline AG6015019 & $1.176^{\star}$ & $0.568^{*}$ & $0.856^{*}$ & 0.023 \\
\hline AG6001208 & $1.379^{*}$ & 0.461 & $0.998^{\star}$ & 0.038 \\
\hline AG6013217 & 0.349 & 0.225 & 0.14 & -0.081 \\
\hline AG6007836 & $0.578^{\star}$ & 0.087 & 0.388 & -0.071 \\
\hline AG6010351 & $-0.824^{*}$ & -0.071 & -0.391 & 0.018 \\
\hline AG6015021 & $1.605^{\star}$ & 0.409 & $1.221^{*}$ & 0.051 \\
\hline
\end{tabular}


Supplemental Table S10. Expression levels of putative ABC-transporter genes, relative to controls ( $\log _{2}$ fold-change). Asterisks indicate significant differential expression at a falsediscovery rate of 0.1 .

\begin{tabular}{|c|c|c|c|c|}
\hline Gene & Esfenvalerate, $12 \mathrm{~h}$ & Esfenvalerate, $24 \mathrm{~h}$ & Thiamethoxam, $12 \mathrm{~h}$ & Thiamethoxam, 24h \\
\hline AG6015836 & $-0.543^{*}$ & -0.072 & -0.019 & 0.093 \\
\hline AG6005556 & $-0.889^{*}$ & -0.11 & $-0.438^{*}$ & 0.003 \\
\hline AG6024387 & 0.367 & 0.119 & -0.055 & -0.102 \\
\hline AG6015816 & $-0.863^{*}$ & -0.062 & $-0.662^{*}$ & -0.071 \\
\hline AG6015846 & 0.16 & 0.24 & 0.044 & 0.149 \\
\hline AG6022731 & $0.965^{\star}$ & 0.293 & 0.4 & -0.036 \\
\hline AG6006018 & -0.351 & -0.032 & -0.161 & -0.027 \\
\hline AG6018120 & -0.289 & 0.307 & -0.085 & 0.128 \\
\hline AG6008081 & -0.126 & -0.122 & -0.084 & -0.079 \\
\hline AG6015849 & 0.093 & -0.065 & 0.216 & -0.192 \\
\hline AG6028993 & -0.15 & -0.135 & 0.006 & -0.044 \\
\hline AG6018122 & $0.628^{*}$ & 0.288 & $0.577^{*}$ & -0.056 \\
\hline AG6005630 & $-0.637^{\star}$ & 0.015 & -0.465 & -0.021 \\
\hline AG6022734 & -0.002 & 0.052 & -0.036 & 0.051 \\
\hline AG6021094 & 0.099 & -0.001 & 0.202 & -0.029 \\
\hline AG6024391 & $0.749^{\star}$ & 0.188 & 0.457 & -0.107 \\
\hline AG6003072 & $-0.666^{*}$ & -0.261 & -0.197 & -0.094 \\
\hline AG6018123 & $0.658^{*}$ & 0.425 & $0.722^{*}$ & -0.012 \\
\hline AG6012176 & -0.356 & -0.105 & -0.367 & -0.134 \\
\hline AG6004243 & $0.464^{*}$ & 0.14 & 0.431 & -0.039 \\
\hline AG6002809 & $-0.863^{*}$ & -0.03 & -0.385 & 0.019 \\
\hline AG6005634 & 0.034 & 0.031 & -0.128 & -0.049 \\
\hline AG6013168 & $0.332^{*}$ & 0.117 & 0.044 & 0.032 \\
\hline AG6016394 & $-0.536^{*}$ & -0.073 & -0.314 & 0.039 \\
\hline AG6015854 & -0.224 & -0.287 & -0.115 & 0.015 \\
\hline AG6010062 & 0.185 & 0.137 & 0.231 & -0.048 \\
\hline AG6021099 & $0.54^{*}$ & 0.089 & 0.221 & -0.074 \\
\hline AG6026114 & -0.097 & -0.119 & 0.265 & 0.004 \\
\hline AG6007859 & $0.513^{*}$ & 0.022 & 0.308 & -0.075 \\
\hline
\end{tabular}


Supplemental Table S10, continued.

\begin{tabular}{|c|c|c|c|c|}
\hline AG6019810 & -0.161 & 0.001 & 0.015 & -0.051 \\
\hline AG6002811 & 0.196 & 0.087 & 0.186 & -0.039 \\
\hline AG6038833 & $-0.693^{*}$ & -0.292 & $-0.459^{*}$ & -0.001 \\
\hline AG6005637 & $-0.849^{*}$ & -0.159 & -0.359 & 0.018 \\
\hline AG6005007 & 0.009 & 0.088 & 0.02 & -0.07 \\
\hline AG6028243 & $0.609^{*}$ & 0.198 & 0.288 & -0.056 \\
\hline AG6020653 & $-0.857^{\star}$ & -0.172 & $-0.538^{\star}$ & 0.036 \\
\hline AG6005639 & $-0.86^{*}$ & -0.343 & -0.383 & -0.069 \\
\hline AG6005640 & $-1.206^{\star}$ & -0.331 & -0.426 & 0.051 \\
\hline AG6000325 & $-0.398^{*}$ & -0.135 & -0.146 & -0.046 \\
\hline AG6013619 & $-0.774^{*}$ & -0.194 & -0.266 & -0.065 \\
\hline AG6007314 & $-0.862^{*}$ & -0.229 & -0.39 & 0.018 \\
\hline AG6010039 & -0.371 & 0.259 & -0.452 & -0.058 \\
\hline AG6002818 & 0.177 & 0.066 & 0.306 & 0.007 \\
\hline AG6024759 & 0.21 & 0.122 & -0.008 & 0.098 \\
\hline AG6001018 & 0.2 & 0.264 & 0.31 & -0.022 \\
\hline AG6011620 & $0.294^{*}$ & 0 & 0.174 & -0.121 \\
\hline AG6025931 & 0.081 & 0.062 & 0.056 & -0.012 \\
\hline AG6011141 & -0.231 & 0.078 & -0.115 & 0.05 \\
\hline AG6015834 & 0.123 & -0.197 & 0.408 & -0.015 \\
\hline AG6014740 & $-0.569^{*}$ & -0.136 & -0.301 & 0.024 \\
\hline AG6023872 & $-0.44^{*}$ & -0.087 & -0.229 & -0.001 \\
\hline AG6015838 & 0.044 & 0.036 & -0.048 & 0.015 \\
\hline AG6019811 & 0.158 & 0.144 & 0.414 & -0.043 \\
\hline AG6019812 & -0.083 & -0.386 & 0.159 & -0.179 \\
\hline AG6018416 & 0.228 & 0.237 & 0.003 & -0.064 \\
\hline AG6015840 & -0.484 & -0.245 & 0.109 & 0.131 \\
\hline AG6005560 & $-0.674^{*}$ & -0.214 & 0.046 & -0.079 \\
\hline AG6012164 & $1.339^{*}$ & 0.294 & $0.965^{\star}$ & -0.038 \\
\hline AG6008223 & 0.103 & -0.025 & 0.114 & -0.004 \\
\hline AG6013156 & $-1.13^{*}$ & -0.293 & $-0.859^{\star}$ & 0.054 \\
\hline AG6015842 & -0.459 & -0.109 & -0.277 & 0.057 \\
\hline AG6005562 & $-0.335^{\star}$ & -0.011 & 0.312 & -0.041 \\
\hline AG6019109 & $-1.104^{*}$ & -0.159 & $-0.575^{\star}$ & -0.019 \\
\hline AG6030986 & -0.325 & -0.006 & -0.111 & 0.181 \\
\hline AG6003905 & 0.188 & 0.083 & 0.189 & -0.067 \\
\hline AG6019757 & $-0.438^{*}$ & -0.132 & $-0.292^{*}$ & -0.033 \\
\hline AG6026683 & -0.075 & 0.048 & -0.002 & -0.09 \\
\hline AG6018420 & $0.823^{*}$ & 0.165 & $0.527^{*}$ & -0.113 \\
\hline AG6013159 & $-0.88^{*}$ & -0.246 & $-0.692^{*}$ & 0.069 \\
\hline
\end{tabular}

